\title{
Procedimiento para la identificación de actores sociales: custodios del patrimonio cultural inmaterial en ciudades patrimoniales
}

\author{
Amparo Gabriela Loza Ibarra*
}

Investigadora independiente

\begin{abstract}
Resumen: Las ciudades consideradas patrimonio de la humanidad esconden en sus centros históricos la riqueza cultural que hoy se ha convertido en un recurso endógeno. El patrimonio cultural inmaterial es un potencial de las ciudades, que amerita especial atención por sus características propias, es importante pensar en políticas públicas destinadas a salvaguardar el patrimonio en los diferentes contextos urbanos. El PCI es un sector que interviene múltiples actores con finalidades e intereses diversos, a veces contradictorios. El PCI es un elemento fundamental de cohesión social, y también en ciertos casos escenario de tensiones y conflictos. De ahí que, la presente investigación se plantea como objetivo diseñar un procedimiento para la identificación de detentores, custodios y practicantes del patrimonio cultural inmaterial en ciudades patrimoniales.
\end{abstract}

Palabras Clave: Procedimiento; Actores sociales; Patrimonio cultural inmaterial; Ciudades patrimoniales

Procedure for the identification of social actors: custodians of Intangible Cultural Heritage in heritage cities.

Abstract: World heritage cities' main heritage is focused on their traditional city centres that represent a significant resource for the local residents. Intangible cultural heritage is particularly important and demands special attention given its specific characteristics, making it vital for it to be safeguarded within all public policies aimed at protecting while promoting heritage in various different urban contexts. Intangible cultural heritage is a sector that involves multiple actors with different and at times conflicting conflicting interests. IIntangible cultural heritage is a fundamental element of social cohesion but, as such, can give rise to tensions and conflicts. This research proposes a procedural model for identifying stakeholders, custodians and target audiences.

Keywords: Procedures; Social agents; Intangible cultural heritage; Heritage cities

\section{Introducción y Marco Teórico}

No se puede hablar de patrimonio sin considerar el análisis conceptual de la cultura. La cultura es el conjunto de conocimientos, procesos, creencias, actitudes, hábitos y formas de comportamiento (Canclini, 1987). A lo señalado, se incluyeron las letras, los modos de vida, los derechos fundamentales del ser humano, los sistemas de valores, las tradiciones y otras capacidades adquiridas por el ser humano (Organización de las Naciones Unidas para la Educación, la Ciencia y la Cultura UNESCO, 1982); donde se elabora la significación de las estructuras sociales, se la reproduce y transforma mediante operaciones simbólicas, (Canclini, 1987; MINCETUR, Perú 2004). Para Coloma (2012), la cultura es una "construcción social netamente humana, que surge de la praxis del hombre en su proceso de apropiación de la naturaleza, que la transforma y se transforma a sí mismo" (pág. 37). La diversidad cultural, se manifiesta en la originalidad y la pluralidad de las identidades que caracterizan a los grupos y las sociedades que componen la humanidad. (UNESCO, 2001). Por lo tanto, la cultura, hoy en día, es reconocida en cada sociedad y, a nivel internacional, los diferentes organismos han propiciados

Investigadora independiente; E-mail: lozagabriela@yahoo.es; https:// orcid.org/0000-0003-2316-5433 
espacios de debate para su conservación, valoración y rescate. Es por eso que cuando se habla de cultura también se habla de patrimonio.

La Ley de Patrimonio Cultural incorpora en su articulado los elementos que han permitido su gestión y protección, al considerar la "pluralidad de las culturas" y la "conservación de sus manifestaciones" (Art. 31, 33 y 34), refiriéndose a "la lengua, la artesanía, las técnicas, la música y la ritualidad", es decir a los elementos que hoy forman parte de la definición del patrimonio cultural inmaterial (PCI). Además, establece como responsabilidad del Instituto Nacional de Patrimonio Cultural (INPC), la "adopción de medidas que tienden a resguardar y conservar tales manifestaciones" en tanto sean los propios pueblos quienes las "hayan reconocido como recurrentes y válidas para su identificación y expresión cultural", que incorpora los principios de identificación y salvaguardia del PCI. (INPC, Guía metodológica para la salvaguardia del Patrimonio Cultural Inmaterial; 2011: 1)

El patrimonio cultural inmaterial (PCI) está conformado por aquellas manifestaciones y expresiones cuyos sabores, conocimientos, técnicas y prácticas, junto con los instrumentos, objetos, artefactos y espacios culturales inherentes, han sido transmitidos de generación en generación, tienen vigencia y son pertinentes para una comunidad, ya que han sido creados constantemente en función de su entorno, realidad, interacción con la naturaleza y su historia. (INPC, Patrimonio Cultural Inmaterial; 2014 :6)

Con este antecedente, el PCI involucra los siguientes ámbitos: las tradiciones y expresiones orales, incluido el idioma; artes del espectáculo como la música tradicional, la danza y el teatro; usos sociales, rituales y actos festivos; conocimientos y usos relacionados con la naturaleza y el universo; técnicas artesanales tradicionales (UNESCO, 2003). El PCI es dinámico, inspirador de un sentimiento de identidad y pertenencia; arraiga la historia de una vida comunitaria; nos ayuda a comprender a los otros y a nosotros mismos (UNESCO, 2009; Ollero, 2010). Para conservar el PCI, hay que asegurar su vialidad, es decir, hay que garantizar su recreación y transmisión de generación en generación. Las comunidades y grupos que practican estas tradiciones tienen que adoptar su propio sistema de transmisión, técnicas y saberes ancestrales, la originalidad y creatividad, el respeto a la diversidad entre comunidades, grupos e individuos para lograr el desarrollo sostenible de tal forma que se promueva la creatividad humana. Las comunidades son el núcleo central del PCI porque solo ellas pueden identificar, practicar, recrear y transmitir su patrimonio cultural (UNESCO 2003).

Ahora bien, por las características propias del PCI, la UNESCO, en el año 2003, enunció la importancia de salvaguardarlo a través "medidas encaminadas a garantizar la viabilidad del patrimonio cultural inmaterial, comprendidas en la identificación, documentación, investigación, preservación, protección, promoción, valorización y transmisión, básicamente a través de la enseñanza formal y no formal y revitalización de este patrimonio en sus distintos aspectos". Su importancia llega a prevalecer aún más por cuando ayuda a forjar y mantener la cohesión social y el diálogo lo que puede proporcionar ingresos y contribuir así a nivelar el camino hacia el desarrollo sostenible.

Con esta base, el Instituto Metropolitano de Patrimonio (IMP) del Distrito Metropolitano de Quito (DMQ) (2011) establece que entre las medidas de salvaguardia de la cultura popular y tradicional, se considera la elaboración de inventarios, la creación de archivos nacionales, la implementación de programas escolares, la creación de instancias gubernamentales, el fomento a la investigación, difusión y medidas de protección enfocadas en los derechos de propiedad intelectual". La elaboración de inventarios del PCI identifica el potencial del territorio y su riqueza viva utilizando sistemas, técnicas e instrumentos, para la recopilación y selección de la información. El inventario es el reconocimiento por parte de los organismos responsables de la conservación, preservación y valorización de la cultura y el patrimonio.

Uno de los aspectos que la UNESCO reconoce como imprescindible al momento de plantear programas de salvaguardia del patrimonio cultural inmaterial en una localidad en cumplimiento del "Consentimiento libre, previo e informado" (CLPI). Este instrumento es clave para garantizar el respeto de los derechos individuales y colectivos de las comunidades y grupos detentores, el fortalecimiento de la participación local y el manejo ético de la información. (INPC, 2011).

Se define como consentimiento a la realización de consultas a los involucrados. Estas deben celebrarse de buena fe y en el marco de un proceso de diálogo que les permita hallar soluciones adecuadas en una atmósfera de respeto recíproco y una participación plena y equitativa (Definiciones formuladas con base a las Directrices del grupo de las Naciones Unidas para el Desarrollo, 2009). Las consultas requieren de tiempo y un sistema eficaz de comunicación entre las partes interesadas. Este proceso puede incluir la opción de negar el consentimiento.

Libre porque no debe existir coerción, intimidación ni manipulación. Este instrumento permite respetar la información relacionada con el PCI, el involucramiento y aceptación por parte de las comunidades y grupos de la población y que las investigaciones producidas retornen a ellas. La salvaguardia del PCI 
está a cargo de los mismos miembros de las comunidades o grupos, por ello es indispensable fortalecer las capacidades locales (Freire, 2011). De ahí que es imprescindible identificar a los detentores del patrimonio que son aquellas personas que disponen del conocimiento, saberes y técnicas que han sido transmitidos oralmente. Los custodios del patrimonio son personas que guardan conocimientos, saberes y técnicas; por último, los practicantes que están interesados en el PCI y desean adquirir experiencia. En el contexto de esta investigación, se los cita como actores sociales del PCI.

Desde el año 1984, se habla de actores sociales como personas o grupos de personas con identidad y valores propios que interactúan en la sociedad mediante la revalorización de la cultura. Los actores sociales son grupos organizados para gestionar procesos vinculados a intereses que los afectan directamente, (Portilla, 2005). Este actor social actúa en el seno de una sociedad, defendiendo la identidad y los intereses de los miembros que la componen en un tejido social en el que se involucra las relaciones de poder, intercambio y negociación (Organización Cielo, 2013). Se consideran estructuras complejas, acumuladores de ideologías, creencias, valores, liderazgo, organización y centros de poder e influencia (Cañizares, 2013). En el ámbito urbano, los actores sociales se dividen en sectores: público, comunidad local, sector privado y turistas. Todos estos actores tienen como finalidad la apropiación simbólica con oportunidades de cambio social (Pírez, 1995). Se identifican con el patrimonio, la infraestructura y la sociedad, (Sousa, 2005).

En América Latina, se reconocen los siguientes actores sociales:

Organizaciones comunitarias: asociaciones más representativas donde las actividades se desarrollan para mejorar las condiciones de vida existentes. Juntas vecinales: organización de un sector frente a las autoridades gubernamentales, encargadas de realizar negociaciones de cualquier tipo entre el sector público y los habitantes del territorio al cual representan. Emprendedores: individuos asociados que desarrollan e implementan proyectos, defendiendo intereses propios o del grupo. Organizaciones no gubernamentales: organismos que defienden ciertos derechos de los habitantes, especialmente de carácter humanitario, económico, social, cultural o político (Kullock D. et al., 1993).

Varios autores mencionados anteriormente coinciden que, para la identificación de actores sociales dentro de un territorio (barrio, comunidad, ciudad), se deben conocer los intereses y las necesidades que poseen dentro de su localidad, tomando en cuenta las siguientes características:

- Grado de influencia (poder de decisión, convocatoria).

- Relaciones con núcleos sociales dentro y fuera de su localidad, (redes sociales).

- Persona que contribuya con ideas, elaboración, planificación y ejecución de proyectos con la finalidad de mejorar el estilo de vida de sus vecinos y del barrio en general.

- Personas que formulen propuestas que tiendan a capitalizar mejor las potencialidades locales.

Por todo lo antes mencionado, se puede decir que los actores sociales son miembros activos de un territorio. La presencia de actores sociales dentro de una localidad permite el desarrollo de proyectos participativos, incluyentes e innovadores, en los cuales se involucran tanto actores sociales locales como actores institucionales públicos y/o privados (Portilla, 2005; Cañizares, 2013; Gobierno Autónomo Descentralizado de Tarqui, 2011). Dentro de los actores sociales, se identifican a los actores sociales claves, individuos cuya participación es indispensable para lograr un objetivo y poseen la capacidad de decidir e influir dentro de un grupo determinado. Entre las características que definen a un actor clave están el formar parte de la sociedad asentada en un área determinada; tiene funciones y atribuciones directas; dispone de capacidades, habilidades, conocimientos, recursos para atender y solventar problemas que se desarrollan en su entorno, y finalmente tiene la capacidad de gestionar y negociar con diversos agentes gubernamentales o privados en beneficio de su localidad (Carvalho, 2011). El actor clave se ubica en un contexto local, regional o nacional, para lo cual se considera el campo de intervención, la función que cumplen, su representatividad, el poder que posee, los recursos que dispone, los objetivos que persigue, las acciones que desarrolla, las relaciones tejidas con otros actores (Gobierno Federal de México, s/a).

Varios países de América Latina han institucionalizado la participación ciudadana y soberanía popular como mecanismos de la democracia representativa directa y comunitaria, uno de ellos es Ecuador.

La Constitución de la República de Ecuador (2008) plantea la participación social como un elemento transversal, generador de política. Dentro de la Constitución, existen varios artículos que hablan sobre los derechos de la participación, la organización del poder como parte de la soberanía popular. Sostiene que la sociedad ecuatoriana está en plenos derechos en cuanto a la participación social y ciudadana como uno de los pilares fundamentales. La participación se orienta a los principios de igualdad, autonomía, deliberación pública, respeto a la diferencia, control popular, solidaridad e interculturalidad. 
Es así que el Ecuador ha armonizado un tejido normativo e institucional que visualiza el derecho a la igualdad, organización y participación ciudadana. Uno de ellos es el Plan Nacional del Buen Vivir (2013 - 2017). El cual hace mención en el Objetivo 1 al Estado democrático y a la Constitución como poder popular, esto quiere decir que el principal agente de acción colectiva es, sin lugar a dudas, el Estado; pero no es el único, sino que además busca recuperar el Estado para la ciudadanía y también fomentar la acción colectiva de la propia sociedad. Fomenta el respeto a la autonomía de organizaciones sociales, promoviendo la participación social y ciudadana, reconoce además la pluralidad de una sociedad incluyente, el respeto a la diversidad. En Plan Nacional de Desarrollo Toda una Vida (2017-2021) en el tercer eje "Mas sociedad, mejor Estado" promueve la participación ciudadana y la construcción de una nueva ética social basada en la transparencia y la solidaridad, un Estado cercano con servicios de calidad y calidez, abierto al diálogo social permanente, así como la soberanía y la paz, posicionando estratégicamente al Ecuador en el mundo.

El Código Orgánico de Ordenamiento Territorial Autonomía y Descentralización (COOTAD) (2012) determina las responsabilidades participativas, la distribución equitativa de los recursos, propone la conformación del sistema de participación ciudadana y reconoce a las parroquias urbanas y rurales, y a los barrios como unidades básicas de participación. La Secretaría Nacional de Planificación y Desarrollo (SENPLADES) (2011) favorece la capacidad organizativa y colectiva de la sociedad, en la formulación, implementación y evaluación de planes sectoriales y territoriales, poniendo énfasis en la colaboración de actores sociales. La Ley Orgánica de Participación Ciudadana (R.O. 175 del 20 de abril de 2010) tiene por objeto propiciar, fomentar y garantizar el ejercicio de los derechos de la participación de las y los ciudadanos, además fortalecer el poder ciudadano y sus formas de expresión, y sentar las bases para el funcionamiento de la democracia participativa.

El Distrito Metropolitano de Quito (DMQ), por su parte, habla de los proceso de participación ciudadana en el desarrollo territorial, social y económico, institucional y diálogo social (Ordenanza $\mathrm{N}^{\mathrm{o}}$ 046). Para lo cual, plantea un sistema institucional y legal con mecanismos que garanticen la participación dependiendo de las nuevas demandas político-económicas y mejoras del sector púbico a través de la descentralización de procesos. En el DMQ se habla del sistema de gestión participativa (Ordenanza N ${ }^{\circ}$ 0187).

Una vez tratada la relación de actores sociales y cómo se la entiende en Ecuador, se pasa a tratar la relación con patrimonio cultural y los actores públicos o decisores responsables de su legislación y gestión, partiendo de las instituciones públicas nacionales.

El Ministerio de Cultura, organismo de poder ejecutivo a nivel nacional y responsable de todos los aspectos culturales del país, ejerce competencia respecto a otros niveles de gestión en todo el territorio nacional. Por su parte, el Instituto Nacional de Patrimonio Cultural (INPC), es una entidad pública que se encarga de investigar y ejercer el control técnico de acuerdo a la política pública emitida por el ente rector de la cultura y el patrimonio para la preservación, conservación, apropiación y uso adecuado del patrimonio cultural material e inmaterial. El INPC desarrolló el Sistema de Información del Patrimonio Cultural del Ecuador (SIPCE), el cual permite conocer cualitativa y cuantitativamente los bienes culturales patrimoniales a través del registro, inventario y catalogación; este proceso permite reconocer los bienes culturales existentes y que en el futuro podrían ser declarados patrimonio cultural.

El sistema de información del Patrimonio Cultural del Ecuador (SIPCE) tiene información de aproximadamente 170.000 bienes culturales, se encuentra en permanente proceso de depuración, homologación y actualización de los datos. El SIPCE se alimenta con información de las fichas de inventario de bienes culturales del Ecuador y puede ser utilizada para consultas, elaboración de estadísticas, mapas temáticos y documentos en PDF. Esta plataforma informática, desarrollada está implementada bajo la normativa y política gubernamental, según el Decreto 1014, que establece como política pública la utilización de software libre en sus sistemas y equipamientos informáticos.

Por otra parte, el Instituto Metropolitano de Patrimonio (IMP) es el ejecutor de la política pública en la conservación del patrimonio del Distrito Metropolitano de Quito (DMQ), se encarga de velar y de cuidar la memoria histórica de Quito; entre sus funciones se encuentra el proteger, promocionar y registrar el Patrimonio Cultural y las Áreas Históricas del DMQ.

La ciudad de Quito y, en especial, el centro histórico guarda una riqueza cultural y patrimonial única, misma que ha permitido el reconocimiento de organismos internacionales como uno de los centros históricos más conservados de Latinoamérica.

Quito se encuentra ubicada en las faldas del estratovolcán Pichincha, tiene una altitud promedio de $2.850 \mathrm{msnm}$, limita al norte con el volcán Casitagua, al sur por el volcán Atacazo, al este por la falla geológica conocida con el nombre de Falla de Quito y al oeste por las faldas del Pichicha. La ciudad 
tiene una dimensión aproximada de $50 \mathrm{~km}$ de longitud en dirección sur-norte y cinco $\mathrm{km}$ de ancho en dirección este-oeste. Debido al acelerado desarrollo urbano y al área de influencia, Quito fue declarada distrito metropolitano en 1993. El DMQ posee el mismo territorio que constituye el cantón Quito, tiene un total de 4230,6 km², cuenta con una población de 2505.344 habitantes (Censo, 2010). El DMQ se divide en nueve administraciones zonales, las cuales están conformadas por 32 parroquias urbanas y 33 parroquias rurales. Una de las parroquias urbanas más importantes de la ciudad es la Parroquia Centro Histórico $(\mathrm{PCH})$, considerada como el área mejor preservada de América; posee bienes culturales materiales e inmateriales gracias a la protección, salvaguardia y gestión de autoridades e instituciones de la ciudad. En 1978, la ciudad de Quito fue declarada como Patrimonio Cultural de la Humanidad por la UNESCO.

El Centro Histórico de Quito (CHQ) tiene una superficie de 376 hectáreas; de las cuales, 264 están edificadas y 112 están destinados al uso del espacio público, infraestructura vial y a áreas no ocupadas. La población residente actual del Centro Histórico, de Quito de acuerdo al último censo (2010), es de 40587 habitantes. Los límites del Centro Histórico de Quito son: al norte las Avenidas Universitaria, Pérez Guerrero, Patria y Ladrón de Guevara. Al sur las calles Los Libertadores, Ferusola, Necochea, María de la Torre, El Cena, Pedro Pinto Guzmán y la quebrada El Conejo. Al este parte de la Av. Simón Bolívar o avenida oriental y al oeste las laderas del Pichincha.

La PCH está formada por varios barrios tradicionales, unidades espaciales ricas en patrimonio cultural inmaterial que albergan tradiciones y costumbres que son el legado de la memoria y herencia propia; espacios de encuentro comunitario, donde se han generado procesos identificativos transmitidos de generación en generación. Por lo cual, cada barrio dispone de una singularidad con característica diferente de convivencia y cotidianidad. Entre los barrios tradicionales, se encuentran La Loma Grande, San Marcos, San Sebastián, San Roque, San Diego, La Victoria y González Suárez.

El objetivo de esta investigación es diseñar un procedimiento para la identificación de detentores, custodios y practicantes del patrimonio cultural inmaterial en ciudades patrimoniales.

\section{Metodología}

La propuesta metodológica de la investigación está compuesta por un procedimiento de tres fases y diez pasos.

Para el estudio de la ciudad de Quito y, en especial, de la PCH se parte de una premisa general: los barrios tradicionales cuentan con potencial patrimonial producto de un transitar histórico, etnográfico y social no visibilizado. Es necesario aprovechar esa oferta cultural por medio de un estudio participativo, activo e incluyente de detentores, custodios y practicantes del patrimonio inmaterial, el cual identifique los recursos patrimoniales que deben ser reconocidos, aquellos que es posible impulsar para diversificar la oferta cultural del CHQ y que incluya, con un conjunto de acuerdos, el libre consentimiento permitido del patrimonio como una medida para salvaguardar el PCI.

La investigación se estructuró en tres fases. La primera se centró en identificar la zona patrimonial (ZP) y actores sociales. Se realizó un levantamiento bibliográfico de los barrios tradicionales que formaron parte de la investigación, luego se identificó a los actores sociales de la ZP.

En la segunda fase, se registró el potencial cultural inmaterial de la ZP, para lo cual se utilizó la metodología del Instituto Nacional de Patrimonio y Cultura (INPC) y el Sistema Patrimonio y Cultura del Ecuador (SIPCE), administrado por la institución antes señalada, para su registro y aprobación.

En la tercera fase, se estructuró una propuesta cultural para salvaguardar el PCI en la ZP.

La primera fase del estudio se dividió, a su vez, en seis pasos: zonificación de la parroquia urbana del Centro Histórico, mapeo de la ZP mediante el Sistema de Información Geográfico (SIG), estudio comparado de metodologías para el levantamiento de actores sociales, identificación de actores sociales en el territorio, identificación de actores sociales claves y, por último, el mapeo de actores sociales claves.

Para el primer paso, se indagó en fuentes secundarias como publicaciones del Instituto de Patrimonio Metropolitano (IMP), entre otras. Se identificó 194,72 hectáreas correspondientes a siete barrios tradicionales que constituyen el cinturón de amortiguamiento y lo más cercano a la zona patrimonial que guarda el PCI por la práctica cotidiana.

El segundo paso consistió en georreferenciar la ZP en la cual se incluyeron los siete barrios tradicionales (San Marcos, La Loma, San Sebastián, San Diego, La Victoria, San Roque y González Suárez) mediante el Sistema de Información Geográfica y 1:4000 
Figura $\mathrm{N}^{\circ}$ 1: Procedimiento para la Identificación de actores sociales del PCI en la ZP

- Zonificaci n de la PCHQ.

- Mapeo de la Zona Patrimonial

(ZP)Estudio Comparado

de metodologías para el

levantamiento de actores

sociales

- Matriz de identificaci $\mathrm{n}$ de

Actores sociales en territorio.

- Matriz de identificaci $n$ de

Actores sociales claves.

- Mapeo de Actores Sociales claves
- Investigaci n bibliogr fica y de campo

- Registro de fichas del PCI en el Sistema

- Mapeo del PCI ( mbitos y sub mbitos) de la ZP
Fortalecimiento de capacidades a los actores claves

- Propuesta cultural para la salvaguardia del PCI en la ZP

Fuente: Elaboración propia

El tercer paso involucró el análisis de ocho metodologías para identificar actores sociales en territorio entre los años 2000 y 2009: Urban Governance Toolkit ONU (2001), Catalina García (2003), Antonio Pozo Solís (2007), Esteban Tapella (2007), Fernando Martínez (2008), la Organization Development Culture and Politics (2009), Swiss Federal Institute of Technology Zurich (s/a) y la Universidad de Deusto (s/a). Se elaboró un cuadro comparado de pasos coincidentes para el levantamiento, identificación y clasificación de actores sociales, los cuales fueron adaptados de acuerdo a las necesidades de la investigación (Matriz $\mathrm{N}^{\circ} 1$ ).

Matriz $\mathrm{N}^{\circ}$ 1: Matriz comparada de metodologías para el estudio de actores sociales

\begin{tabular}{|c|c|c|c|c|c|c|c|c|}
\hline \multicolumn{9}{|c|}{ MATRIZ DE COINCIDENCIAS } \\
\hline \multicolumn{9}{|c|}{ PASOS PARA EL LEVANTAMIENTO, IDENTIFICACIÓN Y CLASIFICACIÓN DE ACTORES SOCIALES } \\
\hline PASOS & $\begin{array}{c}\text { Urban } \\
\text { Governace } \\
\text { Toolkit } \\
\text { ONU (2001) }\end{array}$ & $\begin{array}{c}\text { Catalina } \\
\text { Garcia } \\
\text { (2003) }\end{array}$ & $\begin{array}{c}\text { Antonia } \\
\text { Pozo } \\
\text { Solis } \\
(2007)\end{array}$ & $\begin{array}{c}\text { Esteban } \\
\text { Tapella } \\
(2007)\end{array}$ & $\begin{array}{l}\text { Fernando } \\
\text { Martínes } \\
(\text { (2008) }\end{array}$ & $\begin{array}{c}\text { Organization } \\
\text { Development } \\
\text { culture and } \\
\text { politics (2009) }\end{array}$ & $\begin{array}{c}\text { Swiss } \\
\text { Federal } \\
\text { Institute of } \\
\text { Technology } \\
\text { Zurich (s/a) }\end{array}$ & $\begin{array}{l}\text { Universidad } \\
\text { de Deusto } \\
\text { (s/a) }\end{array}$ \\
\hline Especificar el tema & $\mathbf{X}$ & $\mathbf{x}$ & & & $\mathrm{x}$ & & & \\
\hline $\begin{array}{l}\text { Identificar los actores } \\
\text { sociales }\end{array}$ & $\mathbf{x}$ & $\mathbf{x}$ & $\mathbf{x}$ & $\mathbf{x}$ & $\mathbf{X}$ & $\mathbf{x}$ & $\mathbf{x}$ & $\mathbf{X}$ \\
\hline $\begin{array}{l}\text { Identificar las funciones } \\
\text { y roles }\end{array}$ & & & $\mathrm{X}$ & $\mathbf{x}$ & & $\mathbf{x}$ & $\mathbf{x}$ & $\mathbf{x}$ \\
\hline Precisar & & & & & $\mathrm{X}$ & & & \\
\hline Clasificar & $\mathrm{X}$ & & & & $\mathbf{X}$ & & & \\
\hline $\begin{array}{l}\text { Analizar Posición, Poder, } \\
\text { Interés }\end{array}$ & $\mathrm{X}$ & $\mathrm{X}$ & $\mathrm{X}$ & $\mathrm{X}$ & $\mathrm{X}$ & $\mathrm{X}$ & $\mathrm{X}$ & $\mathrm{X}$ \\
\hline $\begin{array}{l}\text { Elaborar Mapa Poder vs. } \\
\text { Posición }\end{array}$ & $\mathbf{X}$ & $\mathrm{X}$ & $\mathrm{X}$ & $\mathrm{X}$ & $\mathrm{X}$ & & $\mathbf{X}$ & $\mathrm{X}$ \\
\hline $\begin{array}{l}\text { Mapeo de actores y } \\
\text { relaciones }\end{array}$ & & $\mathbf{X}$ & $\mathbf{X}$ & $\mathrm{X}$ & $\mathbf{x}$ & $\mathbf{X}$ & $\mathrm{X}$ & $\mathrm{x}$ \\
\hline $\begin{array}{l}\text { Reconocer redes sociales } \\
\text { existentes }\end{array}$ & & & & $\mathbf{X}$ & $\mathrm{X}$ & & & \\
\hline Revisar y/o analizar & $\mathbf{X}$ & & & & $\mathbf{X}$ & & & \\
\hline $\begin{array}{l}\text { Identificar/diseñar } \\
\text { estrategias }\end{array}$ & $\mathrm{x}$ & & & & $x$ & & & \\
\hline
\end{tabular}

Fuente: Elaboración propia 
Sobre la base de la matriz comparada de metodologías para el estudio de actores sociales. Se determinaron los pasos secuenciales para el levantamiento, identificación y clasificación de actores sociales. Se tomaron como base aquellos pasos que tenían una coincidencia entre los autores sobre el 50\%: a) identificación de actores sociales, el 100\% de los autores investigados lo realizan; b) identificación de funciones y roles, el 62,5\% de los autores realizan este paso; c) análisis de posición, interés y poder, este paso tuvo una coincidencia entre los autores estudiados del 100\%; d) elaboración del mapa de poder y posición, en este paso coincidieron el 87,5\% de los autores analizados; e) el paso de mapeo de actores y relaciones lo utilizan para sus estudios un $87,5 \%$. Con estos resultados, se pasó a definir en qué consistió cada paso que fue considerado para la investigación.

a) Identificación de actores sociales: Para realizar este paso se enlistó a instituciones, grupos organizados, personas individuales, tomando en cuenta algunas características, entre las cuales están:

- Necesarios para la implementación de una propuesta o proyecto.

- Poseen información, experiencia o recursos necesarios.

- Tienen derecho a estar involucrados en la propuesta.

- No están siendo directamente afectados, pero podrían tener un interés en la propuesta o proyecto.

b) Identificación de funciones y roles: El objetivo fue reconocer las principales funciones de los actores sociales respecto del proyecto, así como la descripción de las principales estrategias o modos de vida de los actores; de tal manera que se identificaron las acciones que podrían desarrollar los actores sociales y se perfiló una red de alianzas.

c) Análisis de posición, poder e interés: Se realizó un análisis cualitativo de los actores sociales sobre otros actores sociales, adoptando relaciones predominantes (posición) y niveles de poder con énfasis en el nivel de interés.

d) Elaboración del mapa de Poder vs. Posición: El cuadro o mapa de doble entrada sirvió para ubicar a los actores sociales según su grado de poder (alto, medio o bajo) y posición respecto al proyecto, proceso o propuesta (a favor, indiferente y opuesto). Los investigadores hicieron varias preguntas, en las cuales colaboraron los actores y mediante una "discusión" entre los participantes se procedió a la ubicación de cada actor identificado.

e) Mapeo de actores y relaciones: Se analizó el tipo de relación que puede existir entre los diferentes actores identificados, por ejemplo, relación fuerte de coordinación y trabajo conjunto, relación débil con poca o casi ninguna coordinación y relación de conflicto como principales variables. Sin embargo, existió otra variable a ser utilizada en el mapeo de actores, relaciones estrechas, alianzas y cooperación, relaciones desequilibradas.

El cuarto paso, denominado matriz de identificación de actores sociales en el territorio. En este paso, se comprobó que en la Parroquia Urbana del Centro Histórico y los siete barrios tradicionales (San Marcos, La Loma, San Sebastián, La Victoria, San Diego, San Roque y González Suárez), objeto de esta investigación, confluyen actores sociales públicos y privados de los sectores productivo, turístico, patrimonial y cultural. Para lo cual, se utilizó la técnica de la entrevista a los personeros de las entidades gubernamentales y locales, organismos ejecutores y de gestión del PCI en la ZP. La entrevista tuvo como objeto determinar: funciones o rol; poder, posición, interés e influencia. Estas entrevistas se realizaron en el mes de julio de 2017. Las preguntas estuvieron orientadas a conocer la comunicación entre las diferentes instancias que administran, regulan y promocional al PCI; si existe alguna organización que gestione e involucre a los actores de la ciudad para la toma de decisiones del PCI, y por último quiénes o qué organización debe gestionar el PCI. Posteriormente, se realizó la sistematización de la información, para lo cual se generó una matriz; en el lado izquierdo vertical se colocó el nombre de la institución, en la parte superior de la matriz se colocaron las preguntas y las variables con las que debían responder (Matriz n. ${ }^{\circ}$ 2) Con esta información, se elaboró el gráfico de funciones y rol; poder vs posición; poder vs influencia; interés vs funciones vs poder. Se identificaron actores directos, indirectos; externos e internos; sector público estatal y local, quienes son encargados de gestionar el PCI. A esto se identificaron los actores del sector privado, quienes son los encargados de dinamizar la economía. 
Matriz $\mathrm{N}^{\circ}$ 2: Identificación y nivel de participación de los actores sociales en el Territorio

\begin{tabular}{|c|c|c|c|c|c|c|c|c|c|c|c|c|}
\hline \multirow[t]{3}{*}{ ACTOES } & \multicolumn{2}{|c|}{$\begin{array}{c}\text { El rol de su } \\
\text { organización } \\
\text { es } \\
\text { competencia } \\
\text { directa en } \\
\text { el CHQ y el } \\
\text { patrimonio }\end{array}$} & \multicolumn{2}{|c|}{$\begin{array}{c}\text { Su } \\
\text { organización } \\
\text { tiene } \\
\text { interés en el } \\
\text { patrimonio } \\
\text { cultural } \\
\text { inmaterial del } \\
\text { CHQ }\end{array}$} & \multicolumn{4}{|c|}{$\begin{array}{c}\text { La comunicación entre los } \\
\text { actores sociales del territorio } \\
\text { y actores claves relacionados } \\
\text { con el patrimonio en el CHQ } \\
\text { fluye }\end{array}$} & \multicolumn{2}{|c|}{$\begin{array}{l}\text { Existe alguna } \\
\text { organización } \\
\text { que involucre } \\
\text { a todos los } \\
\text { actores para } \\
\text { la toma de } \\
\text { decisiones } \\
\text { frente el } \\
\text { patrimonio en } \\
\text { el CHQ es }\end{array}$} & \multicolumn{2}{|c|}{$\begin{array}{c}\text { Considera } \\
\text { que su } \\
\text { organización } \\
\text { influye en } \\
\text { la toma de } \\
\text { decisiones } \\
\text { sobre } \\
\text { patrimonio en } \\
\text { el CHQ }\end{array}$} \\
\hline & \multicolumn{2}{|c|}{ FUNCIONES } & \multicolumn{2}{|c|}{ INTERES } & \multicolumn{4}{|c|}{ PODER } & \multicolumn{2}{|c|}{ POSICIÓN } & \multicolumn{2}{|c|}{ INFLUENCIA } \\
\hline & SÍ & NO & D & I & Ex & B & $\mathbf{R}$ & M & $\begin{array}{c}\text { Ex/No } \\
\text { ACT }\end{array}$ & $\begin{array}{c}\text { No } \\
\text { Existe }\end{array}$ & SÍ & NO \\
\hline & & & & & & & & & & & & \\
\hline & & & & & & & & & & & & \\
\hline & & & & & & & & & & & & \\
\hline
\end{tabular}

Fuente: Elaboración propia

$\mathrm{D}=$ Directo

I= Indirecto

$\mathrm{Ex}=$ Excelente

$\mathrm{B}=$ Buena

$\mathrm{R}=$ Regular

$\mathrm{M}=$ Mala

El quinto paso se denominó identificación de actores sociales claves. Se identificaron varios actores sociales claves; para la investigación fue importante saber que en la ZP existían detentores, custodios y practicantes del PCI. Para complementar este cometido, se dividió en dos actividades: a) Visita a los presidentes de cada barrio tradicional (San Marcos, La Loma, San Sebastián, San Diego, La Victoria, San Roque y González Suárez), quienes proporcionaron datos sobre individuos, grupos, colectivos o gremios que se localizaban en su respectivo barrio. Con la información de la salida de campo, se trabajó la Tabla n. ${ }^{\circ} 1$ (Detentores, custodios y practicantes del PCI de la Parroquia $\mathrm{CH}$ ). Los datos que se incluyeron en la tabla fueron nombre, barrio, dirección, teléfono, conocimientos, habilidades o técnicas del PCI y, por último, la valoración como actores sociales claves (detentores, custodios o practicantes).

Tabla $\mathrm{N}^{\circ}$ 1: Detentores, custodios y practicantes del PCI de la Parroquia Centro Histórico

\begin{tabular}{|c|c|c|c|c|c|c|}
\hline Nombre & Barrio & Direccion & Teléfono & D & C & P \\
\hline & & & & & \\
\hline & & & & & \\
\hline
\end{tabular}

Fuente: Elaboración propia

Una vez levantada esta información, se pasó a la actividad b) Identificación de los emprendimientos culturales, los cuales podrían convertirse en un futuro en oferta cultural con base en el PCI en la ZP. Los datos que se registraron en este instrumento fueron nombre, ámbito, subámbito y categoría a la cual corresponde la actividad de cada actor social clave (Matriz n. ${ }^{\circ} 3$ ).

Tabla Nº 2: Emprendimientos Culturales del PCI en la ZP

\begin{tabular}{|c|c|c|c|}
\hline \multicolumn{5}{|c|}{ Conocimientos, saberes y técnicas en base al PCI } \\
\hline Nombre & Ámbito & Subámbito & Categoría \\
\hline & & & \\
\hline & & & \\
\hline
\end{tabular}

Fuente: Elaboración propia 
El sexto paso consistió en mapear actores sociales claves por barrio y, de acuerdo a su valoración, fueron registrados en el mapa mediante el Sistema de Identificación Georeferencial (SIG) en una escala de 1:4000

La segunda fase se denominó "Registro del Potencial Cultural Inmaterial de la ZP", cuyo objetivo fue registrar la riqueza patrimonial inmaterial con la que cuentan los barrios tradicionales de la Parroquia Centro Histórico mediante metodologías probadas para este efecto. En esta fase, se detalló el paso séptimo y octavo.

$\mathrm{Al}$ séptimo paso, se lo denominó Investigación bibliográfica y de campo del PCI de la Parroquia Centro Histórico. Este paso tuvo cuatro actividades: a) investigación bibliográfica que se realizó en fuentes secundarias; b) entrevistas a detentores, custodios y practicantes sobre sus conocimientos, saberes y técnicas con base en el PCI; c) registro en audio, video y fotografías; d) Testeo de información primaria y secundaria.

El octavo paso se denominó registro de fichas del PCI de la PCH en el SIPCE. Este paso tuvo tres actividades: a) permiso para el registro de la información al SIPCE (Sistema Patrimonio Cultural del Ecuador) mediante oficio al INPC, quienes asignaron un usuario y una clave para el ingreso de información; b) el registro en el SIPCE se realizó en los meses de agosto, septiembre y octubre de 2017; c) aprobación por parte de la técnica encargada.

El noveno paso tuvo como objetivo el mapeo del PCI de la ZP por ámbitos, subámbitos y categorías mediante el SIG en una escala de 1:4000

La tercera fase se denominó "Propuesta Cultural para salvaguardar el PCI de la ZP", la cual tuvo como objetivo estructurar una propuesta cultural para salvaguardar el PCI de la ZP con la participación activa de los actores sociales claves. Para complementar esta fase se desarrollaron los pasos décimo y undécimo.

El décimo paso se llamó fortalecimiento de capacidades a los actores sociales claves del PCI de la ZP. Para complementar este paso se desarrollaron cuatro actividades: a) encuesta sobre la importancia al interpretar el PCI, se aplicaron sesenta encuestas en el mes de octubre de 2017 con tres preguntas fundamentales: si le interesaría participar en actividades de capacitación, importancia del fortalecimiento de competencias para interpretar el PCI, beneficios de la capacitación; b) resultados de la encuesta para lo que se utilizó el SPSS; c) estructuración del taller para el fortalecimiento de capacidades para interpretar el PCI; d) ejecución del taller, se realizó un taller en el mes de octubre de 2017 con el objetivo de incentivar a todos los actores sociales claves a empoderarse del patrimonio cultural inmaterial, así como también impartir conocimientos y resultados obtenidos durante los dos años de investigación.

En el undécimo paso, se identificó una propuesta cultural, que tuvo como objetivo visibilizar a detentores, custodios y practicantes del PCI de la PCH mediante ferias culturales en el Centro Cultural Metropolitano. Esta propuesta se presentó en la convocatoria 2018, organizada por la Secretaría de Cultura del DMQ.

\section{Resultados}

Durante los dos años de investigación, se obtuvieron los siguientes resultados.

\section{Fase I: Identificación de la Zona Patrimonial (ZP) y Actores Sociales}

Paso 1. La PCH tiene una superficie de 376 hectáreas, de las cuales se consideró únicamente 194.72 que corresponden a los siete barrios tradicionales investigados (La Loma Grande, San Marcos, San Sebastián, González Suárez, San Roque, La Victoria y San Diego).

\section{Tabla $N^{\circ}$ 3: Identificación de la Zona Patrimonial}

\begin{tabular}{|l|c|}
\hline \multicolumn{1}{|c|}{ Barrio } & Has \\
\hline La Loma Grande & 3314 \\
\hline San Marcos & 16.79 \\
\hline San Sebastián & 27.38 \\
\hline González Suárez & 57.68 \\
\hline San Roque & 22.28 \\
\hline La Victoria & 19.10 \\
\hline San Diego & 18.35 \\
\hline TOTAL HAS & $\mathbf{1 9 4 . 7 2}$ \\
\hline
\end{tabular}

Fuente: Elaboración propia 
Paso 2. Mediante el uso del SIG, se pudo mapear la ZP y los siete barrios tradicionales.

\section{Mapa $\mathrm{N}^{\circ}$ 1: Zona Patrimonio del CHQ}
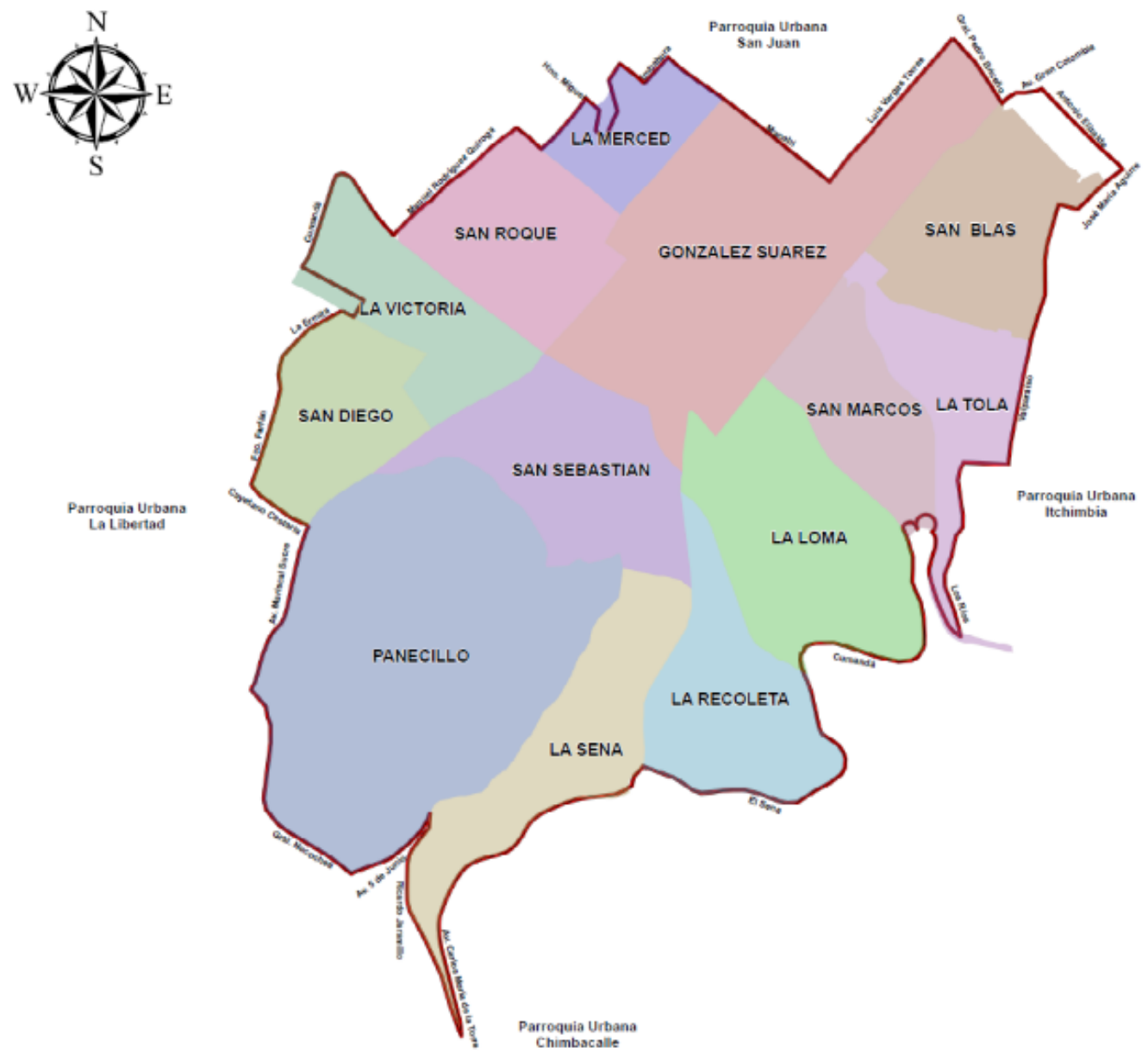

Fuente: Elaboración propia

Paso 3. Para determinar las funciones o roles; el interés, poder, posición e influencia que tienen las entidades gubernamentales en cuanto al patrimonio cultural inmaterial, se ejecutó la matriz de identificación y nivel de participación de los actores sociales en el territorio, obteniendo como resultados la gráfica con los cruces respectivos, los cuales muestran claramente que las Instituciones Gubernamentales que cumplen las funciones o roles en cuanto a la competencia directa del manejo del PCI en el CHQ son las entidades directamente relacionadas con la Cultura, por otro lado el interés que prestan las instituciones hacia el PCI es dividido, directamente se involucran las instituciones que manejan directamente la cultura dentro del CHQ en este caso se encuentran el INPC, DMQ - Cultura y el IMP, e indirectamente MC, MINTUR y UIOTurismo. En cuanto al poder las instituciones en su mayoría coinciden que la comunicación con los actores sociales claves es bueno. La posición de las instituciones frente al involucramiento y la opinión de los actores sociales claves no existen, son directamente las instituciones gubernamentales las que toman las decisiones en lo referente al manejo del PCI en el CHQ. Finalmente la influencia es claramente de las instituciones que están a cargo del manejo del PCI en el CHQ. 
Matriz $\mathrm{N}^{\circ}$ 3: Identificación y nivel de participación de los actores sociales en el Territorio

\begin{tabular}{|c|c|c|c|c|c|c|c|c|c|c|c|c|}
\hline \multirow[t]{3}{*}{ Actores } & \multicolumn{2}{|c|}{$\begin{array}{l}\text { El rol de su } \\
\text { organización } \\
\text { es } \\
\text { competencia } \\
\text { directa en } \\
\text { el CHQ y el } \\
\text { patrimonio }\end{array}$} & \multicolumn{2}{|c|}{$\begin{array}{l}\text { Su } \\
\text { organización } \\
\text { tiene } \\
\text { interés en el } \\
\text { patrimonio } \\
\text { cultural } \\
\text { inmaterial } \\
\text { del CHQ }\end{array}$} & \multicolumn{4}{|c|}{$\begin{array}{l}\text { La comunicación entre } \\
\text { los actores sociales del } \\
\text { territorio y actores } \\
\text { claves relacionados } \\
\text { con el patrimonio en el } \\
\text { CHQ fluye }\end{array}$} & \multicolumn{2}{|c|}{$\begin{array}{l}\text { Existe alguna } \\
\text { organización } \\
\text { que involucre a } \\
\text { todos los actores } \\
\text { para la toma de } \\
\text { decisiones frente } \\
\text { el patrimonio en } \\
\text { el CHQ es }\end{array}$} & \multicolumn{2}{|c|}{$\begin{array}{l}\text { Considera } \\
\text { que su } \\
\text { organización } \\
\text { influye en } \\
\text { la toma de } \\
\text { decisiones } \\
\text { sobre } \\
\text { patrimonio } \\
\text { en el CHQ }\end{array}$} \\
\hline & \multicolumn{2}{|c|}{ Función } & \multicolumn{2}{|c|}{ Interés } & \multicolumn{4}{|c|}{ Poder } & \multicolumn{2}{|c|}{ Posicion } & \multicolumn{2}{|c|}{ Influencia } \\
\hline & SI & NO & D & $\mathbf{I}$ & Ex & B & $\mathbf{R}$ & $\mathbf{M}$ & E/N ACT & NO/E & SÍ & NO \\
\hline $\begin{array}{l}\text { Ministerio de } \\
\text { Cultura }\end{array}$ & $\mathbf{X}$ & & & $\mathrm{X}$ & & $\mathbf{X}$ & & & & $\mathbf{X}$ & $\mathbf{X}$ & \\
\hline $\begin{array}{l}\text { Ministerio de } \\
\text { Turismo }\end{array}$ & & $\mathrm{X}$ & & $\mathrm{X}$ & & $\mathbf{X}$ & & & & $\mathrm{X}$ & & $\mathrm{X}$ \\
\hline $\begin{array}{l}\text { Instituto } \\
\text { Nacional de } \\
\text { Patrimonio } \\
\end{array}$ & $\mathbf{X}$ & & $\mathbf{X}$ & & $\mathrm{X}$ & & & & $\mathbf{X}$ & & $\mathrm{X}$ & \\
\hline $\begin{array}{l}\text { Municipio de } \\
\text { DMQ - Cultura } \\
\end{array}$ & $\mathbf{X}$ & & $\mathbf{X}$ & & & $\mathbf{X}$ & & & $\mathrm{X}$ & & $\mathbf{X}$ & \\
\hline $\begin{array}{l}\text { Instituto } \\
\text { Metropolitano de } \\
\text { Patrimonio } \\
\end{array}$ & $\mathbf{X}$ & & $\mathbf{X}$ & & & $\mathbf{X}$ & & & & $\mathrm{X}$ & $\mathbf{X}$ & \\
\hline Quito Turismo & & $\mathrm{X}$ & & $\mathrm{X}$ & & & $\mathrm{X}$ & & & $\mathbf{X}$ & & $\mathbf{X}$ \\
\hline
\end{tabular}

Fuente: Elaboración propia

$\mathrm{D}=$ Directo

I= Indirecto

$\mathrm{Ex}=$ Excelente

$\mathrm{B}=$ Buena

$\mathrm{R}=$ Regular

$\mathrm{M}=$ Mala
$\mathrm{Ex} /$ No $\mathrm{ACT}=$ Existe pero no involucra a los actores sociales No Existe

Figura $\mathrm{N}^{\circ}$ 2: Identificación y nivel de participación de los Actores Sociales en Territorio

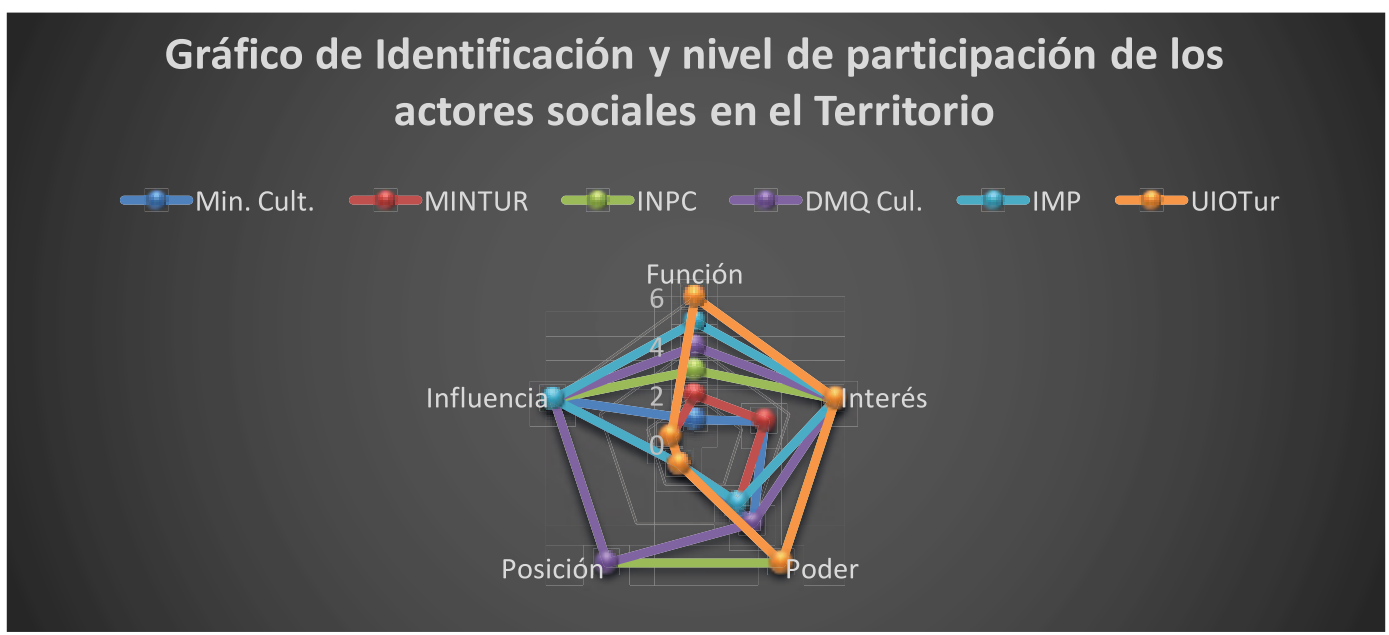

Fuente: Elaboración propia

Paso 4. La siguiente tabla es el resultado de la investigación realizada en campo, en la que se obtiene como resultado el nombre, el barrio al que pertenecen, la dirección en la cual se encuentra el PCI y, en algunos casos, los números telefónicos. Parte fundamental de esta tabla es la verificación de detentores, custodios y/o practicantes del PCI. 
Tabla No 4: Identificación de Actores Sociales custodios del PCI

\begin{tabular}{|c|c|c|c|c|c|c|}
\hline \multicolumn{7}{|c|}{ Detentores, Custodios y Practicantes del PCI de la Parroquia Centro Histórico } \\
\hline Nombre & Barrio & Dirección & Teléfono & D & $\mathbf{C}$ & $\mathbf{P}$ \\
\hline Hólger Paz & San Sebastián & Borrero Oe1-75 y Loja & & & & $\mathrm{X}$ \\
\hline Edison Aguirre & San Sebastián & Borrero Oe1-212 y Loja & 3463434 & & & $\mathrm{X}$ \\
\hline Segundo Ocaña & San Roque & Rocafuerte Oe6-111 y Cuenca & & $\mathrm{X}$ & & \\
\hline César Anchala & San Roque & Benalcázar S1-124 y 24 de Mayo & 2287635 & $\mathrm{X}$ & & \\
\hline Gonzalo Gallardo & San Roque & Rocafuerte N1-33 Imbabura & 2288981 & $\mathrm{X}$ & & \\
\hline $\begin{array}{l}\text { Francisco } \\
\text { Calvopiña }\end{array}$ & San Roque & Rocafuerte Oe8-108 y Chimborazo & 2281582 & $\mathrm{X}$ & & \\
\hline Eduardo Pichucho & San Roque & Rocafuerte y Chimborazo & & $\mathrm{X}$ & & \\
\hline Patricia Pavón & San Roque & $\begin{array}{l}\text { Rocafuerte y Chimborazo Mercado } \\
\text { San Francisco Puesto \# } 27\end{array}$ & & $\mathrm{X}$ & & \\
\hline Rosa Lagla & San Roque & $\begin{array}{l}\text { Rocafuerte y Chimborazo Mercado } \\
\text { San Francisco }\end{array}$ & & $\mathrm{X}$ & & \\
\hline Rosa González & San Roque & Rocafuerte Oe6-122 y Cuenca & & $\mathrm{X}$ & & \\
\hline Gonzalo Rivera & San Roque & Rocafuerte Oe8-67 & & & $\mathrm{X}$ & \\
\hline Rocío Carrión & San Roque & Rocafuerte N1-33 e Imbabura & & & $\mathrm{X}$ & \\
\hline $\begin{array}{l}\text { Comunidad } \\
\text { Franciscana }\end{array}$ & San Roque & Cuenca 477 & 2281124 & & $\mathrm{X}$ & \\
\hline Rosa Bonilla & San Roque & Rocafuerte Oe8-13 e Imbabura & & $\mathrm{X}$ & & \\
\hline José Barrera & San Marcos & Junín E3-03 & 2280753 & $\mathrm{X}$ & & \\
\hline Viviana Barragán & San Marcos & Jaime Gutiérrez y Junín & & & $\mathrm{X}$ & \\
\hline Marcelo Ruíz & San Marcos & Montufar N4-05 y Junín & 098322739 & $\mathrm{X}$ & & \\
\hline Angelita Líger & San Marcos & Junín E3-43 & & $\mathrm{X}$ & & \\
\hline $\begin{array}{l}\text { Mercedes } \\
\text { Quintana }\end{array}$ & San Marcos & Espejo Oe1-85 y Flores & 2284000 & & $\mathrm{X}$ & \\
\hline Nancy Carrillo & San Marcos & Almeida y Pichincha & & $\mathrm{X}$ & & \\
\hline César Guacán & San Diego & $\begin{array}{l}\text { Chimborazo Oe6-16 y Bahía de } \\
\text { Caráquez }\end{array}$ & 2583475 & $\mathrm{X}$ & & \\
\hline Juan López & San Diego & Imbabura 1-65 & & & $\mathrm{X}$ & \\
\hline Fernando Rivera & San Diego & Imbabura 1-63 & 2218766 & $\mathrm{X}$ & & \\
\hline Luis Cabrera & San Diego & Imbabura 1-62 & 2572365 & $\mathrm{X}$ & & \\
\hline Luis Almachi & La Victoria & Carabobo Oe8-10 e Imbabura & 2953801 & $\mathrm{X}$ & & \\
\hline Rubén Montes & La Victoria & $\begin{array}{l}\text { Bahía de Caráquez S3-43 y } 24 \text { de } \\
\text { Mayo }\end{array}$ & & $\mathrm{X}$ & & \\
\hline Segundo Chili & La Victoria & $\begin{array}{l}\text { Bahía de Caráquez S3-41 y } 24 \text { de } \\
\text { Mayo }\end{array}$ & & $\mathrm{X}$ & & \\
\hline Julio Panamá & La Victoria & Imbabura S4-36 y Ambato & & $\mathrm{X}$ & & \\
\hline Patricia Sánchez & La Victoria & Imbabura S2-27 y 24 de Mayo & & $\mathrm{X}$ & & \\
\hline Marco Rubio & La Loma & Rocafuerte y Zaldumbide & 099812320 & & & $\mathrm{X}$ \\
\hline Freddy Rosero & $\begin{array}{l}\text { González } \\
\text { Suárez }\end{array}$ & Rocafuerte Oe5-10 y García Moreno & & & $\mathrm{X}$ & \\
\hline
\end{tabular}




\begin{tabular}{|c|c|c|c|c|c|c|}
\hline \multicolumn{7}{|c|}{ Detentores, Custodios y Practicantes del PCI de la Parroquia Centro Histórico } \\
\hline Nombre & Barrio & Dirección & Teléfono & $\mathbf{D}$ & $\mathbf{C}$ & $\mathbf{P}$ \\
\hline Rosario Chiliguano & \begin{tabular}{|l|} 
González \\
Suárez
\end{tabular} & Rocafuerte Oe5-32 y García Moreno & & $\mathrm{X}$ & & \\
\hline Nora Hidalgo & \begin{tabular}{|l|} 
González \\
Suárez
\end{tabular} & Rocafuerte Oe4-20 y Venezuela & & $\mathrm{X}$ & & \\
\hline Oswaldo Cascante & \begin{tabular}{|l|} 
González \\
Suárez
\end{tabular} & Rocafuerte Oe3-59 y Venezuela & & $\mathrm{X}$ & & \\
\hline Guillermo Báez & \begin{tabular}{|l|} 
González \\
Suárez
\end{tabular} & Sucre 391 y García Moreno & & $\mathrm{X}$ & & \\
\hline Eduardo Muñóz & \begin{tabular}{|l|} 
González \\
Suárez
\end{tabular} & Flores N2-92 y Sucre & 2952905 & $\mathrm{X}$ & & \\
\hline Inés Puertas & \begin{tabular}{|l|} 
González \\
Suárez
\end{tabular} & García Moreno N2-15 y Bolívar & 2281222 & $\mathrm{X}$ & & \\
\hline Juan Meneses & $\begin{array}{l}\text { González } \\
\text { Suárez }\end{array}$ & Olmedo Oe4-78 y García Moreno & & $\mathrm{X}$ & & \\
\hline Eulalia Guevara & \begin{tabular}{|l|} 
González \\
Suárez
\end{tabular} & $\begin{array}{l}\text { Bajos de la Iglesia La Catedral } \\
\text { Local Oe4-31 }\end{array}$ & 2957840 & $\mathrm{X}$ & & \\
\hline Jordan Morales & \begin{tabular}{|l|} 
González \\
Suárez
\end{tabular} & Benalcázar N3-123 y Espejo & 099568364 & $\mathrm{X}$ & & \\
\hline Víctor Jácome & $\begin{array}{l}\text { González } \\
\text { Suárez }\end{array}$ & Manabí 420 y Guayaquil & 2284731 & $\mathrm{X}$ & & \\
\hline Soledad Espinosa & \begin{tabular}{|l} 
González \\
Suárez
\end{tabular} & Rocafuerte Oe4-98 y García Moreno & 2956181 & $\mathrm{X}$ & & \\
\hline Nelson Castro & $\begin{array}{l}\text { González } \\
\text { Suárez }\end{array}$ & Venezuela N1-51 & 099682631 & $\mathrm{X}$ & & \\
\hline Nelson Pinto & \begin{tabular}{|l} 
González \\
Suárez
\end{tabular} & García Moreno N4-35 & & & & $\mathrm{X}$ \\
\hline Tomy Baca & $\begin{array}{l}\text { González } \\
\text { Suárez }\end{array}$ & Benalcázar N3-119 y Espejo & 2284823 & $\mathrm{X}$ & & \\
\hline $\begin{array}{l}\text { Magdalena } \\
\text { Espinosa }\end{array}$ & $\begin{array}{l}\text { González } \\
\text { Suárez }\end{array}$ & Venezuela N1-91 y Bolívar & 2582991 & $\mathrm{X}$ & & \\
\hline Luis Silva & \begin{tabular}{|l|} 
González \\
Suárez
\end{tabular} & García Moreno, Psj Amador local A9 & 2287448 & $\mathrm{X}$ & & \\
\hline José Chaguaro & $\begin{array}{l}\text { González } \\
\text { Suárez }\end{array}$ & Guayaquil N5-59 y Mejía & 2285082 & $\mathrm{X}$ & & \\
\hline
\end{tabular}

Fuente: Elaboración propia

Paso 5. A continuación, se muestra el mapa de actores sociales identificados de acuerdo a la valoración del PCI, para lo cual fue necesario el uso de un GPS que permitió georreferenciar a cada uno de ellos. 


\section{Mapa $\mathbf{N}^{\circ}$ 2: Actores Sociales Identificados}

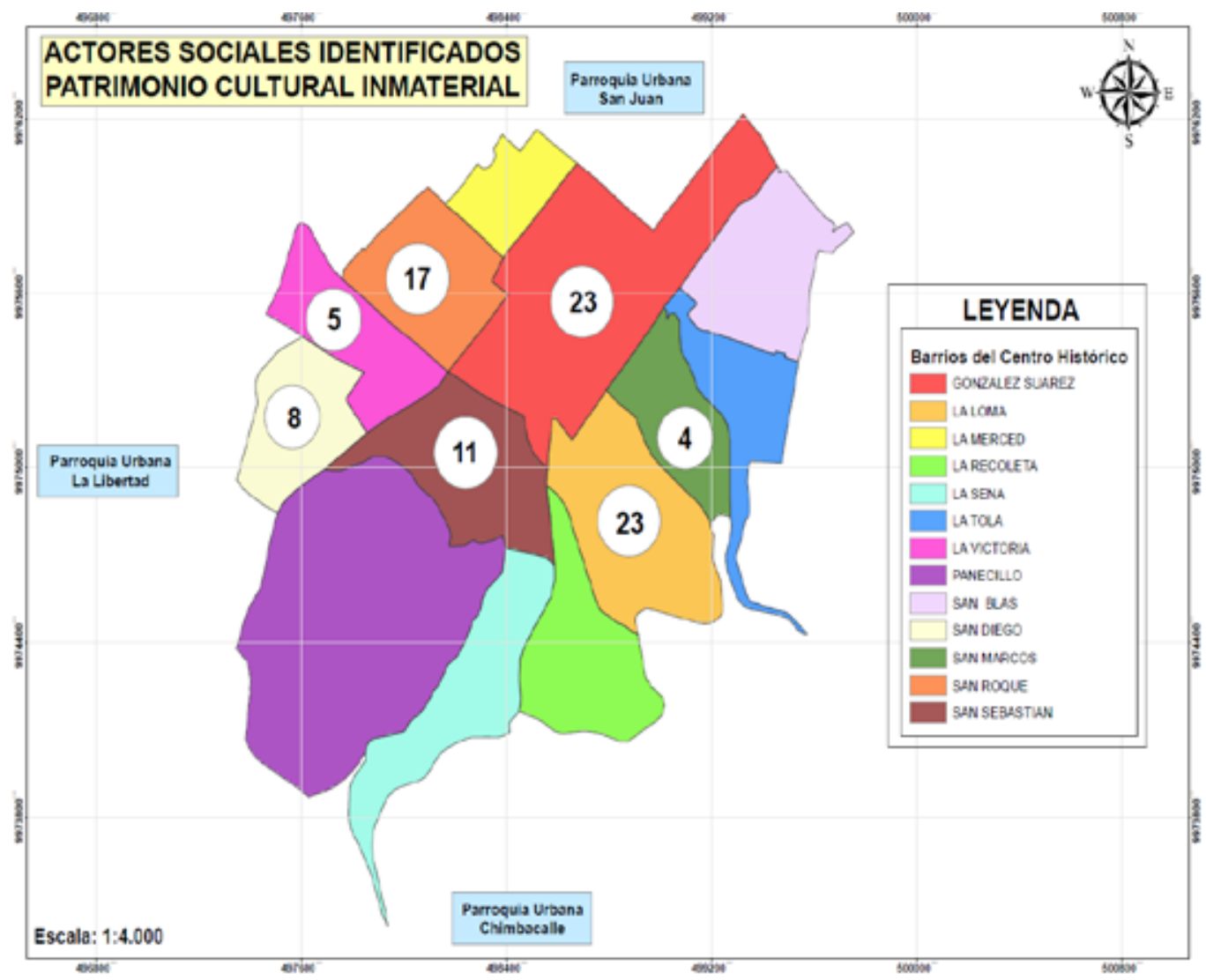

Fuente: Elaboración propia

Fase II: Registro del Potencial Cultural Inmaterial de la ZP

Paso 6. Para determinar los conocimientos, saberes y técnicas que poseen los actores sociales claves se realizó la siguiente tabla, en la que se puede observar el ámbito, subámbito y categoría en los cuales se desenvuelven. 
Tabla No 5: Conocimientos, Saberes y Técnicas Artesanales

\begin{tabular}{|c|c|c|c|}
\hline \multicolumn{4}{|c|}{ Conocimientos, saberes y técnicas con base en el pci } \\
\hline Nombre & Ámbito & Subámbito & Categoría \\
\hline Hólger Paz & Usos sociales, rituales y actos festivos & Fiestas & $\begin{array}{l}\text { Fiesta o } \\
\text { conmemoraciones } \\
\text { religiosas }\end{array}$ \\
\hline Edison Aguirre & Artes del espectáculo & Música & \\
\hline Segundo Ocaña & Usos sociales, rituales y actos festivos & Oficios Tradicionales & Sombrerero \\
\hline César Anchala & Usos sociales, rituales y actos festivos & Oficios Tradicionales & Sombrerero \\
\hline Gonzalo Gallardo & Usos sociales, rituales y actos festivos & Oficios Tradicionales & $\begin{array}{l}\text { Imaginero / } \\
\text { restaurador }\end{array}$ \\
\hline $\begin{array}{l}\text { Francisco } \\
\text { Calvopiña }\end{array}$ & Usos sociales, rituales y actos festivos & Oficios Tradicionales & Molinero \\
\hline Eduardo Pichucho & Usos sociales, rituales y actos festivos & Oficios Tradicionales & Molinero \\
\hline Patricia Pavón & $\begin{array}{l}\text { Conocimientos y usos relacionados con } \\
\text { la naturaleza y el universo }\end{array}$ & Medicina tradicional & Medicina natural \\
\hline Rosa Lagla & $\begin{array}{l}\text { Conocimientos y usos relacionados con } \\
\text { la naturaleza y el universo }\end{array}$ & Medicina tradicional & Medicina ancestral \\
\hline Rosa González & $\begin{array}{l}\text { Conocimientos y usos relacionados con } \\
\text { la naturaleza y el universo }\end{array}$ & Medicina tradicional & \\
\hline Gonzalo Rivera & Tradiciones y expresiones orales & Leyendas & $\begin{array}{l}\text { Leyenda asociada a } \\
\text { apariciones de seres } \\
\text { sobrenaturales }\end{array}$ \\
\hline $\begin{array}{l}\text { Comunidad } \\
\text { Franciscana }\end{array}$ & Tradiciones y expresiones orales & Leyendas & $\begin{array}{l}\text { Leyenda asociada a } \\
\text { apariciones de seres } \\
\text { sobrenaturales }\end{array}$ \\
\hline Rosa Bonilla & $\begin{array}{l}\text { Conocimientos y usos relacionados con } \\
\text { la naturaleza y el universo }\end{array}$ & Gastronomía & $\begin{array}{l}\text { Gastronomía } \\
\text { Cotidiana }\end{array}$ \\
\hline José Barrera & Técnicas artesanales tradicionales & $\begin{array}{l}\text { Técnicas artesanales } \\
\text { tradicionales }\end{array}$ & \\
\hline Viviana Barragán & Artes del espectáculo & Juegos tradicionales & Juegos infantiles \\
\hline Marcelo Ruíz & Técnicas artesanales tradicionales & $\begin{array}{l}\text { Técnicas artesanales } \\
\text { tradicionales }\end{array}$ & Ebanistería \\
\hline Angelita Líger & $\begin{array}{l}\text { Conocimientos y usos relacionados con } \\
\text { la naturaleza y el universo }\end{array}$ & Gastronomía & $\begin{array}{l}\text { Gastronomía } \\
\text { Cotidiana }\end{array}$ \\
\hline $\begin{array}{l}\text { Mercedes } \\
\text { Quintana }\end{array}$ & $\begin{array}{l}\text { Conocimientos y usos relacionados con } \\
\text { la naturaleza y el universo }\end{array}$ & Medicina tradicional & Medicina natural \\
\hline Nancy Carrillo & $\begin{array}{l}\text { Conocimientos y usos relacionados con } \\
\text { la naturaleza y el universo }\end{array}$ & Gastronomía & $\begin{array}{l}\text { Gastronomía } \\
\text { Cotidiana }\end{array}$ \\
\hline César Guacán & Técnicas artesanales tradicionales & $\begin{array}{l}\text { Técnicas artesanales } \\
\text { tradicionales }\end{array}$ & $\begin{array}{l}\text { Fabricación de } \\
\text { instrumentos } \\
\text { musicales }\end{array}$ \\
\hline Juan López & Tradiciones y expresiones orales & Leyendas & $\begin{array}{l}\text { Leyenda asociada a } \\
\text { apariciones de seres } \\
\text { sobrenaturales }\end{array}$ \\
\hline Fernando Rivera & Técnicas artesanales tradicionales & $\begin{array}{l}\text { Técnicas artesanales } \\
\text { tradicionales }\end{array}$ & Marmolería \\
\hline Luis Cabrera & Técnicas artesanales tradicionales & $\begin{array}{l}\text { Técnicas artesanales } \\
\text { tradicionales }\end{array}$ & Marmolería \\
\hline
\end{tabular}




\begin{tabular}{|c|c|c|c|}
\hline \multicolumn{4}{|c|}{ Conocimientos, saberes y técnicas con base en el pci } \\
\hline Nombre & Ámbito & Subámbito & Categoría \\
\hline Luis Almachi & Usos sociales, rituales y actos festivos & Oficios tradicionales & Carpintero \\
\hline Rubén Montes & Técnicas artesanales tradicionales & $\begin{array}{l}\text { Técnicas artesanales } \\
\text { tradicionales }\end{array}$ & Hojalatería \\
\hline Segundo Chili & Usos sociales, rituales y actos festivos & Oficios tradicionales & Peluquero \\
\hline Julio Panamá & Técnicas artesanales tradicionales & $\begin{array}{l}\text { Técnicas artesanales } \\
\text { tradicionales }\end{array}$ & Marmolería \\
\hline Patricia Sánchez & $\begin{array}{l}\text { Conocimientos y usos relacionados con } \\
\text { la naturaleza y el universo }\end{array}$ & Gastronomía & $\begin{array}{l}\text { Gastronomía } \\
\text { Cotidiana }\end{array}$ \\
\hline Marco Rubio & $\begin{array}{l}\text { Tradiciones y expresiones orales } \\
\text { Artes del espectáculo }\end{array}$ & $\begin{array}{l}\text { Leyendas } \\
\text { Juegos tradicionales }\end{array}$ & $\begin{array}{l}\text { Leyenda } \\
\text { Juegos infantiles }\end{array}$ \\
\hline Freddy Rosero & $\begin{array}{l}\text { Conocimientos y usos relacionados con } \\
\text { la naturaleza y el universo }\end{array}$ & Medicina tradicional & \\
\hline $\begin{array}{l}\text { Rosario } \\
\text { Chiliguano }\end{array}$ & Usos sociales, rituales y actos festivos & Oficios tradicionales & Costurera \\
\hline Nora Hidalgo & Usos sociales, rituales y actos festivos & Oficios tradicionales & Costurera \\
\hline Oswaldo Cascante & Técnicas artesanales tradicionales & $\begin{array}{l}\text { Técnicas artesanales } \\
\text { tradicionales }\end{array}$ & Talabartería \\
\hline Guillermo Báez & $\begin{array}{l}\text { Conocimientos y usos relacionados con } \\
\text { la naturaleza y el universo }\end{array}$ & Gastronomía & $\begin{array}{l}\text { Gastronomía } \\
\text { Cotidiana }\end{array}$ \\
\hline Eduardo Muñóz & Técnicas artesanales tradicionales & $\begin{array}{l}\text { Técnicas artesanales } \\
\text { tradicionales }\end{array}$ & Cerería \\
\hline Inés Puertas & $\begin{array}{l}\text { Conocimientos y usos relacionados con } \\
\text { la naturaleza y el universo }\end{array}$ & Medicina tradicional & \\
\hline Juan Meneses & $\begin{array}{l}\text { Conocimientos y usos relacionados con } \\
\text { la naturaleza y el universo }\end{array}$ & Gastronomía & $\begin{array}{l}\text { Gastronomía } \\
\text { Cotidiana }\end{array}$ \\
\hline Eulalia Guevara & $\begin{array}{l}\text { Conocimientos y usos relacionados con } \\
\text { la naturaleza y el universo }\end{array}$ & Gastronomía & $\begin{array}{l}\text { Gastronomía } \\
\text { Cotidiana }\end{array}$ \\
\hline Jordan Morales & $\begin{array}{l}\text { Conocimientos y usos relacionados con } \\
\text { la naturaleza y el universo }\end{array}$ & Gastronomía & $\begin{array}{l}\text { Gastronomía } \\
\text { Cotidiana }\end{array}$ \\
\hline Víctor Jácome & Usos sociales, rituales y actos festivos & Oficios tradicionales & Fotógrafo \\
\hline Soledad Espinosa & Técnicas artesanales tradicionales & $\begin{array}{l}\text { Técnicas artesanales } \\
\text { tradicionales }\end{array}$ & Imaginería \\
\hline Nelson Castro & Usos sociales, rituales y actos festivos & Oficios tradicionales & Fotógrafo \\
\hline Nelson Pinto & Usos sociales, rituales y actos festivos & Oficios tradicionales & Peluquero \\
\hline Tomy Baca & $\begin{array}{l}\text { Conocimientos y usos relacionados con } \\
\text { la naturaleza y el universo }\end{array}$ & Gastronomía & $\begin{array}{l}\text { Gastronomía } \\
\text { Cotidiana }\end{array}$ \\
\hline $\begin{array}{l}\text { Magdalena } \\
\text { Espinosa }\end{array}$ & $\begin{array}{l}\text { Conocimientos y usos relacionados con } \\
\text { la naturaleza y el universo }\end{array}$ & Gastronomía & $\begin{array}{l}\text { Gastronomía } \\
\text { Cotidiana }\end{array}$ \\
\hline Luis Silva & Usos sociales, rituales y actos festivos & Oficios tradicionales & Fotógrafo \\
\hline José Chaguaro & $\begin{array}{l}\text { Conocimientos y usos relacionados con } \\
\text { la naturaleza y el universo }\end{array}$ & Gastronomía & $\begin{array}{l}\text { Gastronomía } \\
\text { Cotidiana }\end{array}$ \\
\hline
\end{tabular}

Fuente: Elaboración propia

Paso 7. Para el ingreso de los datos investigados al SIPCE, se solicitó el 2 de marzo de 2017 mediante oficio dirigido a Karen Cevallos, funcionaria del Instituto Nacional de Patrimonio, la designación de usuario y clave del sistema. Una vez aprobada la solicitud se procedió al ingreso de la información en las fichas modelo, las cuales fueron revisadas y aprobadas por Karina Fonseca, técnica del INPC, entre los meses de agosto a octubre. Se ingresaron 110 fichas y se obtuvo la aprobación de 105. 
Figura $\mathrm{N}^{\circ}$ 3: Ingreso de los datos patrimoniales inmateriales al SIPCE
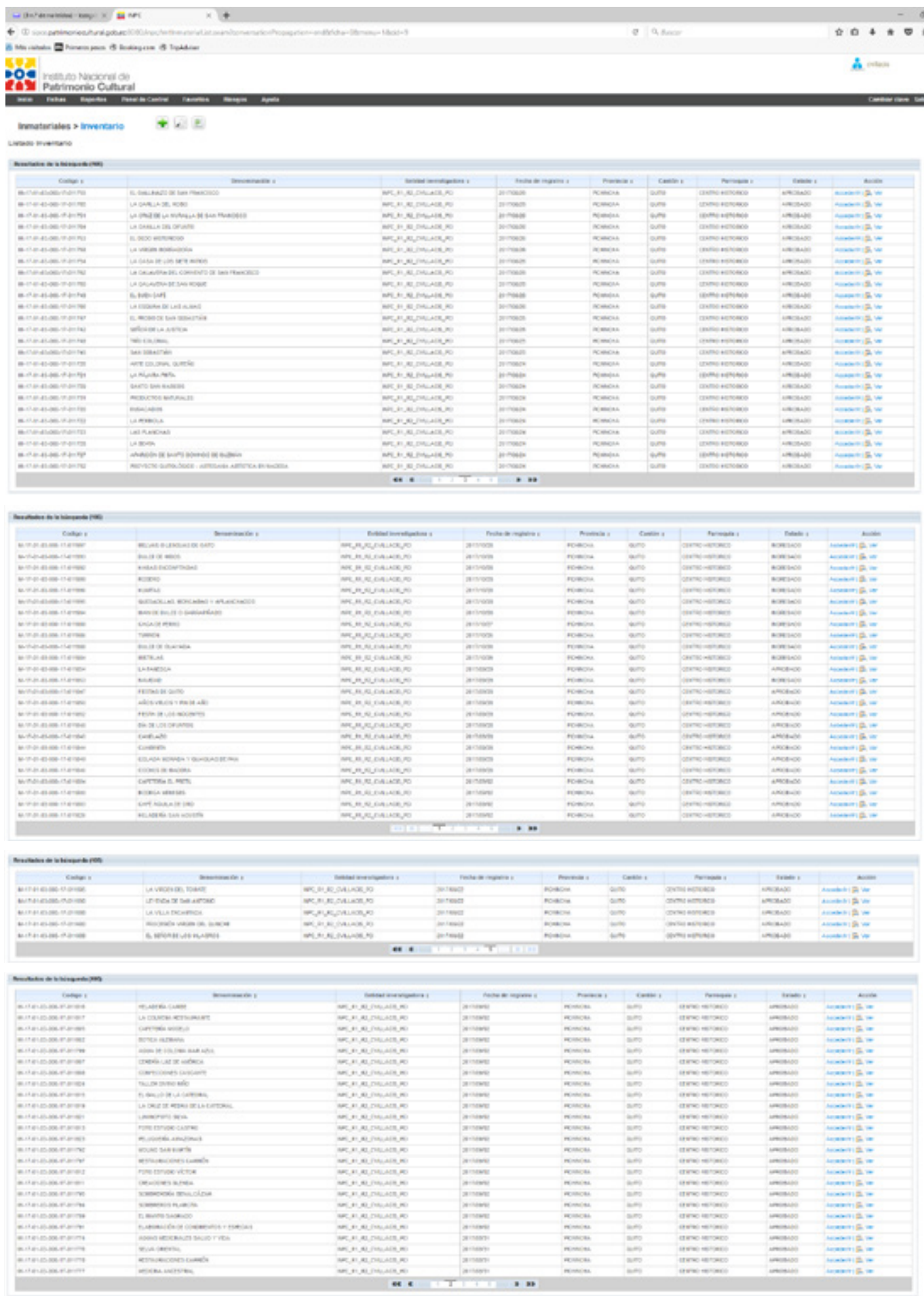


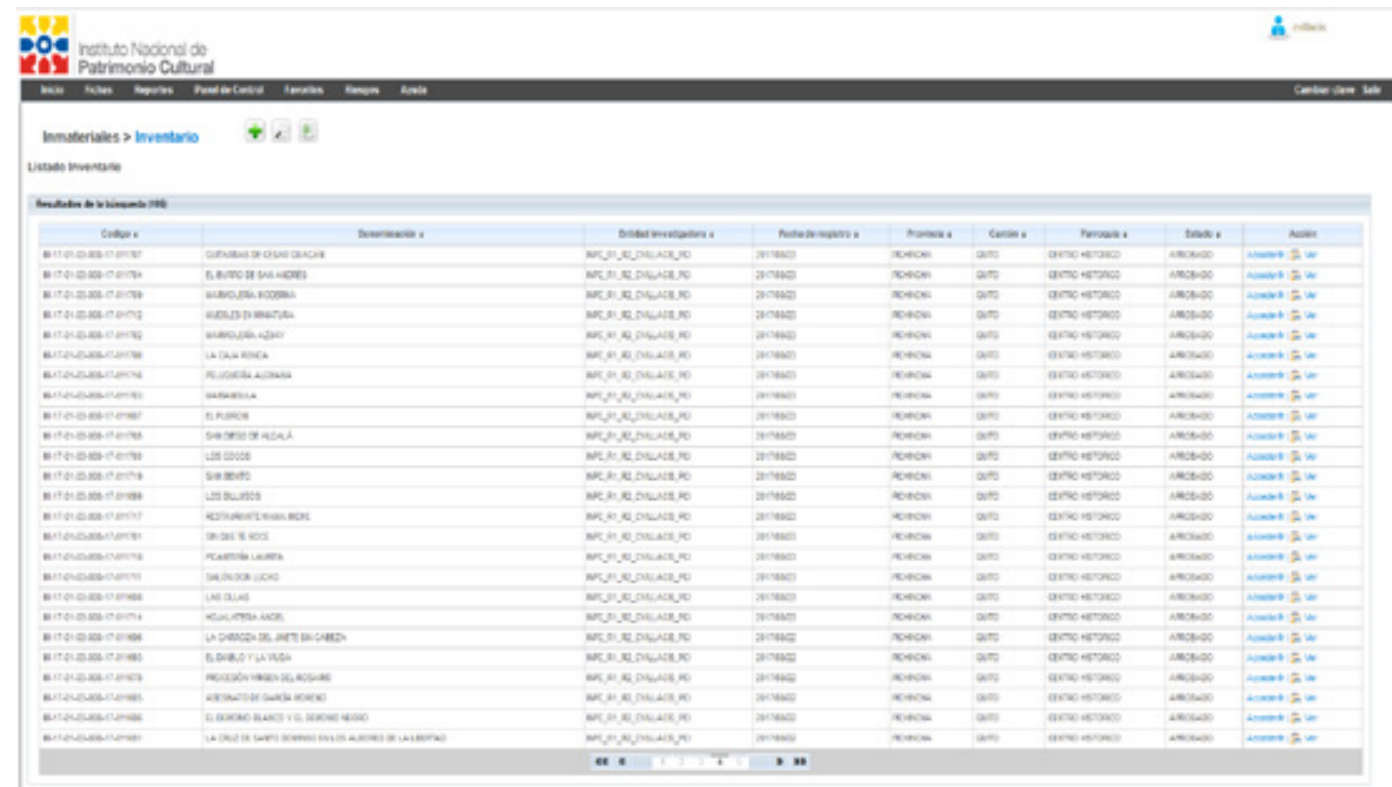

Con la finalidad de verificar y evidenciar la información, se puede ingresar al sistema con los siguientes pasos:

1) Ingresar a Google.

2) En el buscador colocar SIPCE.

3) Ingresan y en la página principal se encuentra MÓDULO DE VISTA, dar un clic.

4) Ingresan en búsqueda por palabra.

5) Seleccionar categoría INMATERIAL.

6) En Filtros de búsqueda, colocar lo siguiente Provincia: Pichincha, Cantón: Quito, Parroquia: Centro Histórico, Tipo de Ficha: Bienes de Interés Patrimonial y, finalmente, poner BUSCAR.

7) En la parte derecha se enlistarán las fichas con el nombre del Patrimonio Cultural Inmaterial.

8) Se podrán descargar las fichas en formato PDF como se muestra a continuación. 
Figura $N^{\circ}$ 4: Ingreso de Información Patrimonial en las Fichas del SIPCE

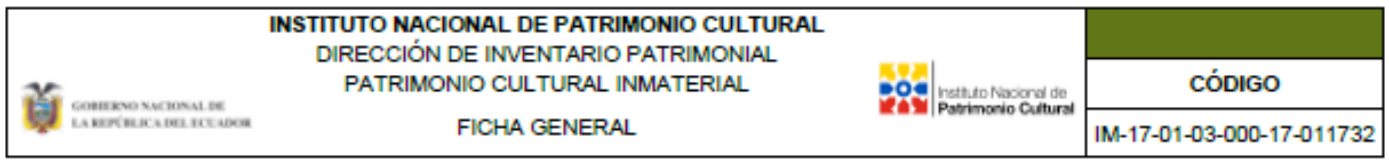

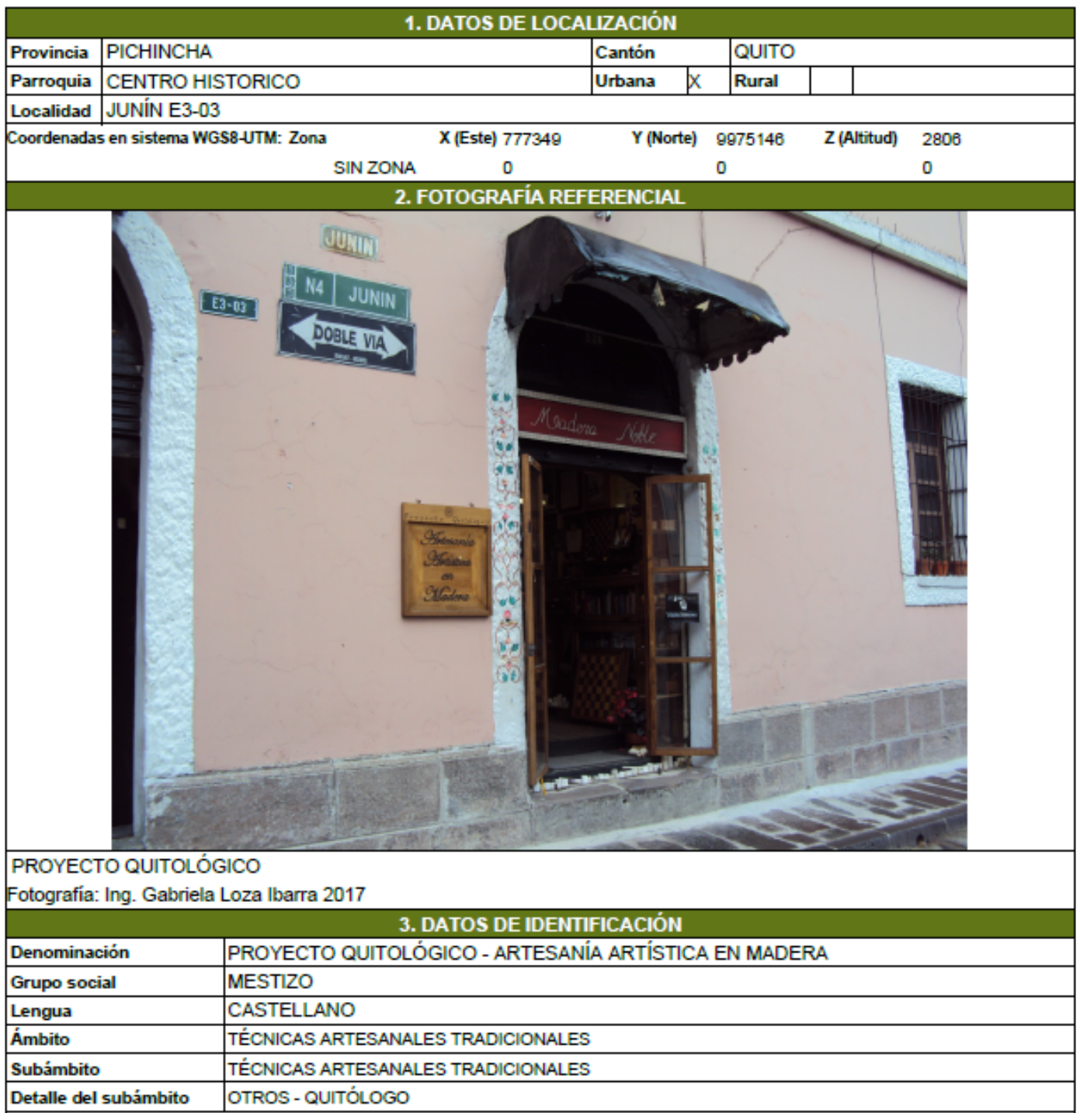


4. DESCRIPCIÓN DE LA MANIFESTACIÓN

DESCRIPCION: José Barrera menciona que está en el barrio 10 años con su negocio, en el cual realiza la técnica de taraceo.

La técnica artesanal tiene desde hace 30 años, menciona que es una persona autodidacta, inició su trabajo con el objetivo de recuperar la Escuela Quiteña.

Menciona que se ubicó en San Marcos, porque es un barrio que mantienen su identidad y pertenencia, es un barrio que históricamente no se juntó con el resto de barrios de la ciudad, por decisión de los habitantes. El barrio no ha cambiado con el pasar de los años, más bien todo lo contrario se mantiene.

El negocio inicia por la pasión de José Barrera por la madera, él tuvo la oportunidad de hacer un estudio completo acerca de los claustros de las diferentes iglesias de Quito, esto despierta el interés por la quitología. El gusto por la artesanía hace que trabaje con pasión.

Estudioso de las técnicas realizadas y enseñadas en ese entonces en la Escuela Quiteña, el taraceo (técnica árabe que se trata de incrustar en la madera otros materiales como: tagua, hueso, mármol, concha nácar, concha carey, hilos de plata entre otros materiales).

Para realizar el trabajo José utiliza materiales como: gubias, taladro, varios tipos de cinceles y caladoras, los cuales ha ido elaborando él mismo de acuerdo a las necesidades que ha tenido en su taller.

Barrera menciona que es fanático de los bargueños (mueble utilizado como caja fuerte para guardar pertenencias, joyas o documentos y su origen milenario se niega a desaparecer, un mueble de origen hispanoárabe que se destaca por su variedad de compartimientos.)

Todas sus artesanías están a la venta para cualquier persona que llegue a visitarlo, también realiza obras bajo pedido Entre los objetos que elabora se encuentran: baúles, joyeros y cajas con texturas diversas, dados, sillas, tableros de ajedrez, entre otras artesanías.

José menciona: "jamás repito un trabajo, cada creación debe ser única, debe tener algo diferente que le caracterice y salga de la cotidianidad"

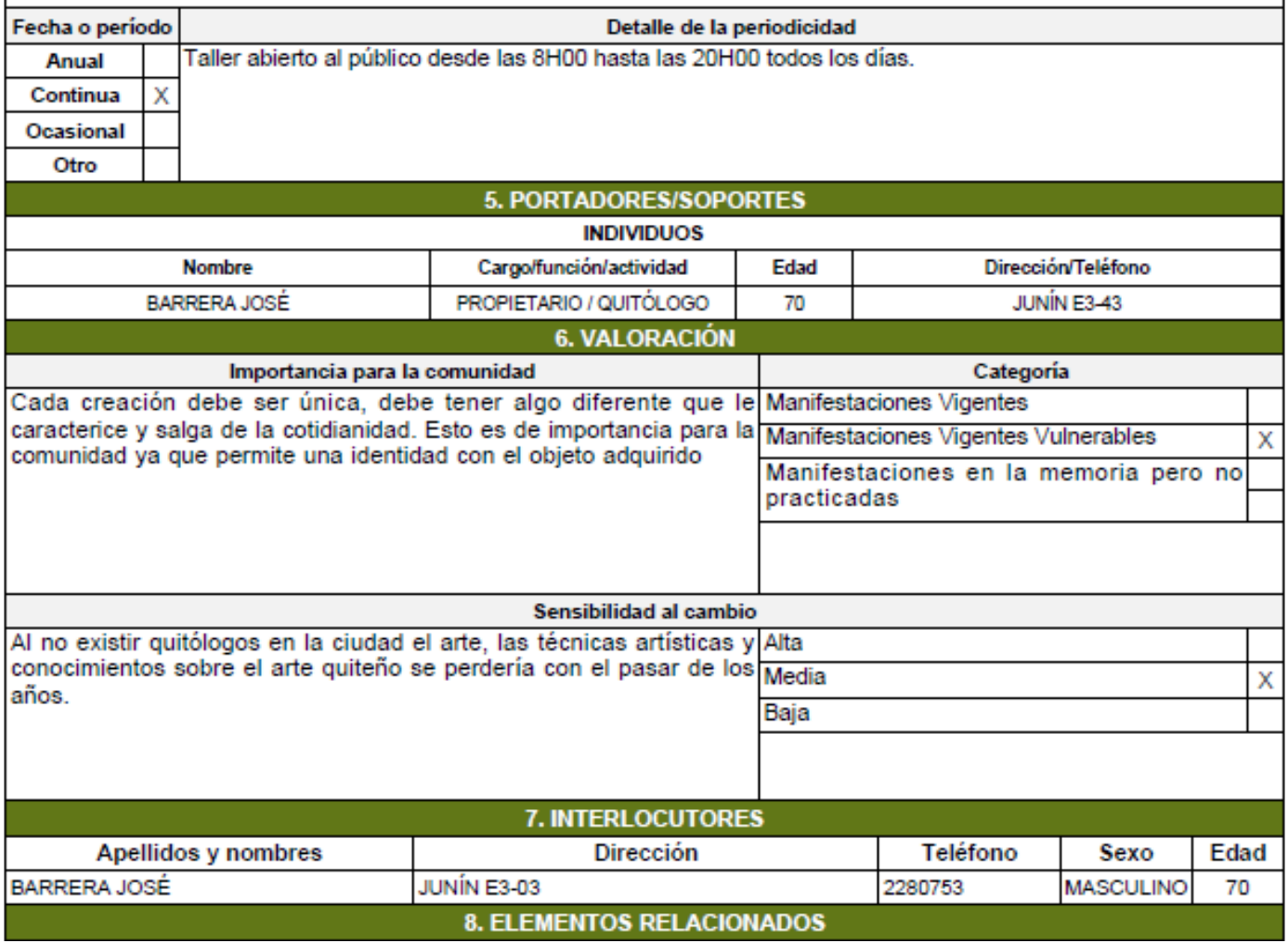




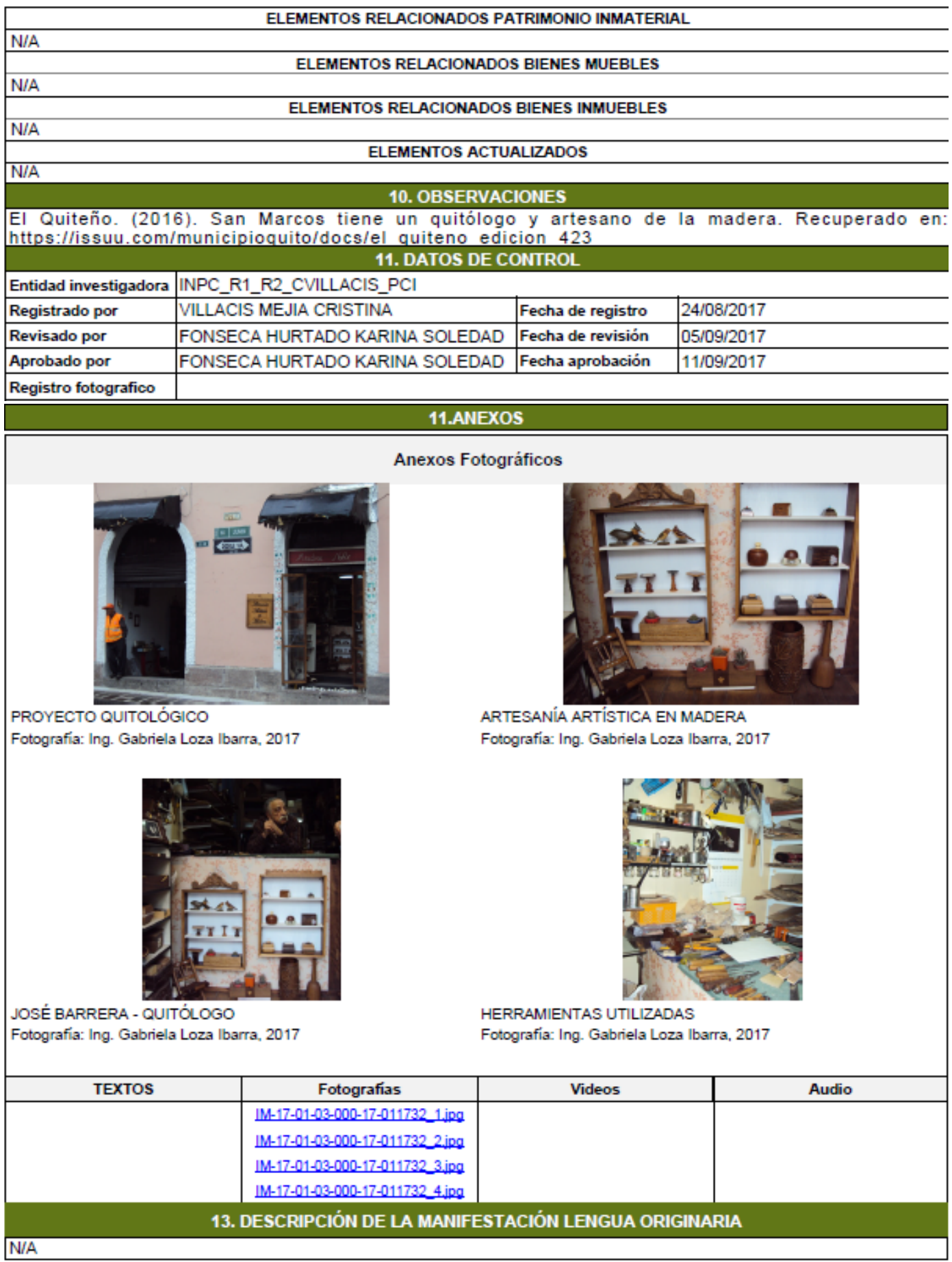


Paso 8. Con los mismos puntos georreferenciales que se ubicaron a los actores sociales en el mapa, se determinó la ubicación de los ámbitos y subámbitos, los mismos que se pueden evidenciar de acuerdo a los colores que se han colocado en los siete barrios tradicionales.

\section{Mapa No 3: Patrimonio Cultural Inmaterial del CHQ - Ámbitos}

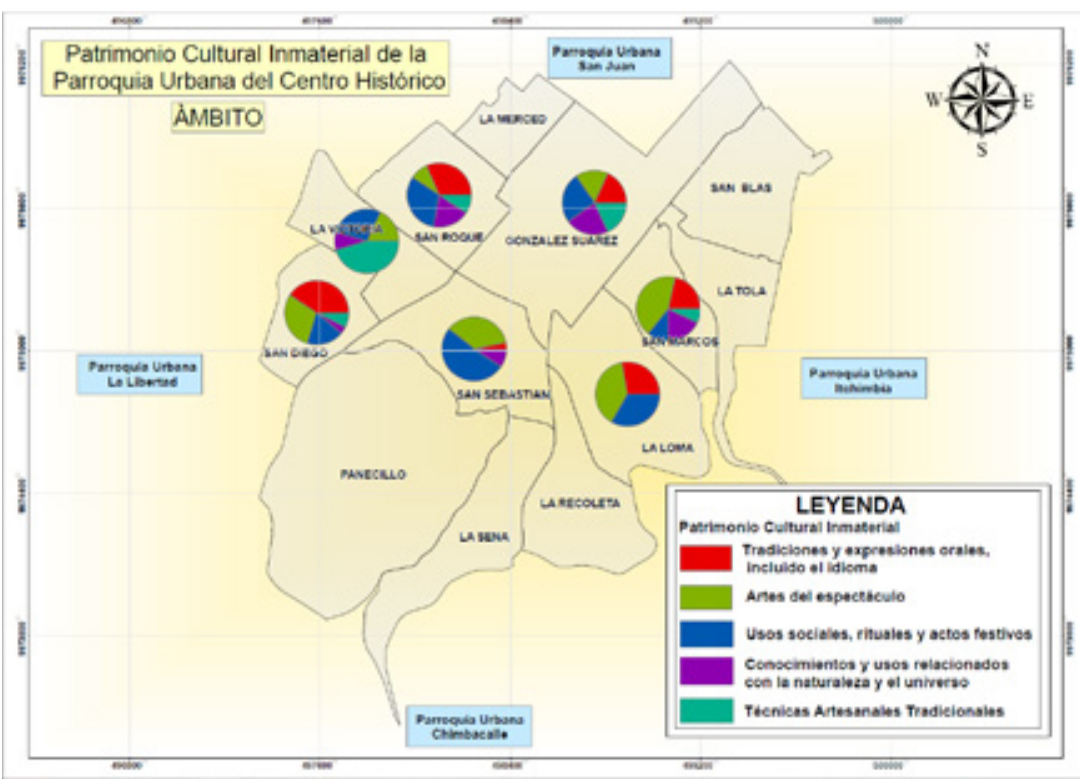

Fuente: Elaboración propia

\section{Mapa No 4: Patrimonio Cultural Inmaterial del CHQ - Subámbitos}

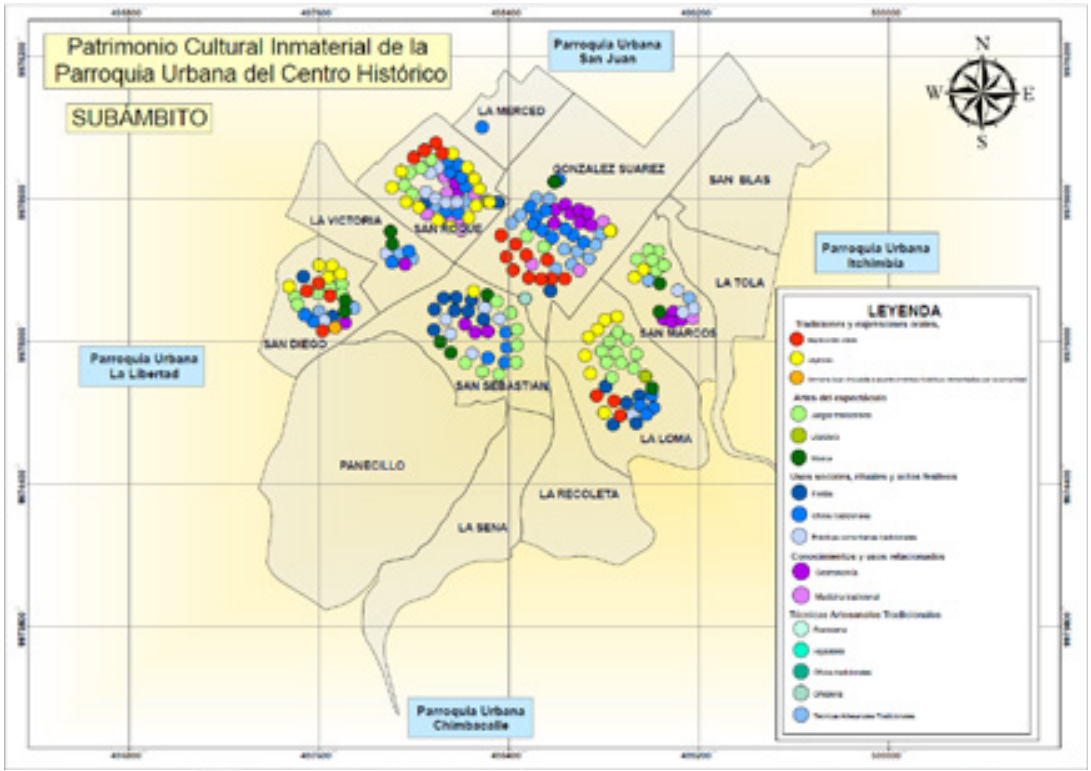

Fuente: Elaboración propia 


\section{Fase III: Propuesta cultural para salvaguardar el PCI de la ZP}

Paso 9. Se aplicaron sesenta encuestas en el mes de octubre de 2017, con tres preguntas fundamentales, y se obtuvieron los siguientes resultados:

1. El $62 \%$ de los encuestados respondió que está totalmente de acuerdo; el 20\%, algo interesados; el $8 \%$ no responde a la pregunta; las personas desinteresadas en adquirir capacitación corresponde al $7 \%$, y las personas indecisas es el $3 \%$.

Figura $\mathrm{N}^{\circ}$ 4: Resultados de la encuesta realizada a los Custodios del Patrimonio Inmaterial

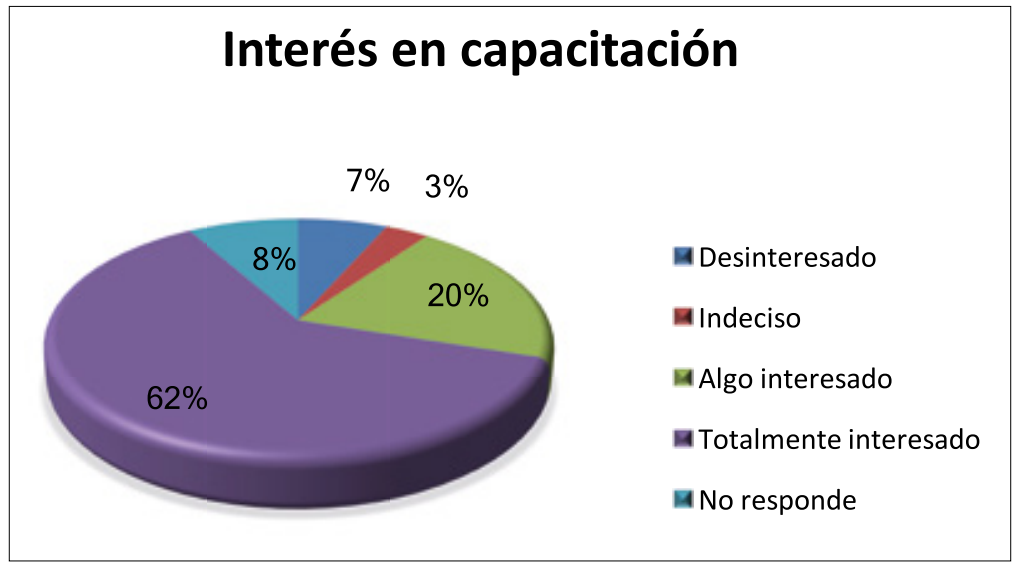

Fuente: Elaboración propia

2. El $63 \%$ de los encuestados coincide que el fortalecimiento del PCI es muy importante; el 17\%, importante; el 16\% no responde la pregunta; mientras que los encuestados que se mantienen indiferentes y poco interesados coinciden con el $2 \%$ respectivamente.

Figura $\mathrm{N}^{\circ}$ 5: Resultados de la encuesta sobre la importancia del fortalecimiento del PCI

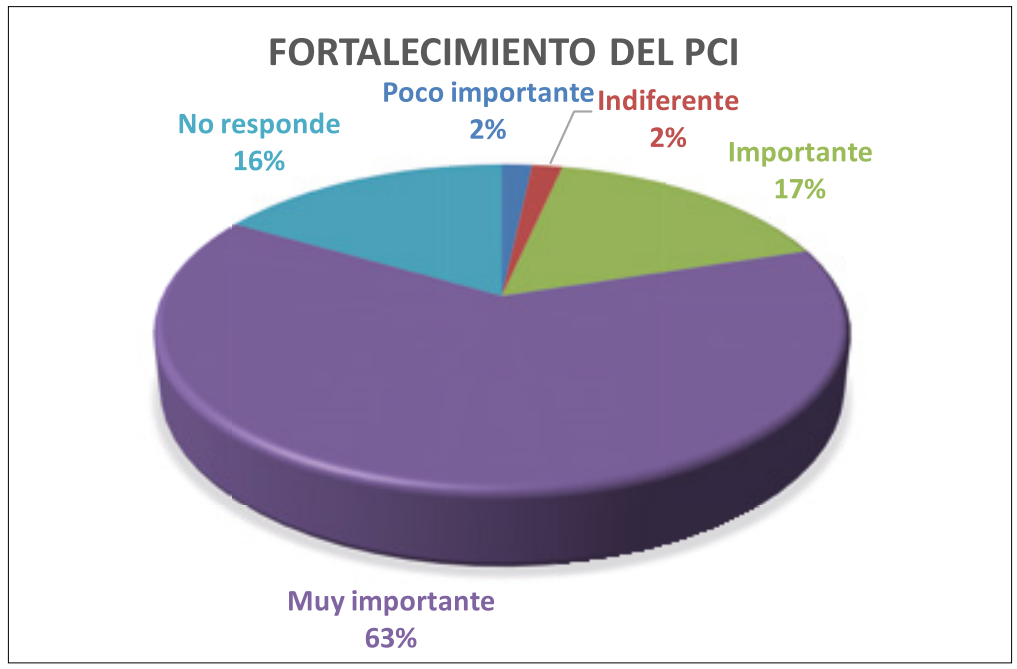

Fuente: Elaboración propia 
3. Se puede determinar que los actores sociales encuestados dan importancia al fortalecimiento de competencias en lo referente al empoderamiento y orgullo del PCI con un 50\%, seguido de la sensibilización en temas patrimoniales con el $48.3 \%$, el respeto a la diversidad cultural el $46.7 \%$, la participación de proyectos el $43.3 \%$ y con menor importancia la atención al público el 35\% y la minimización de impactos el $33.3 \%$.

\section{Figura $N^{\circ}$ 6: Resultados de la encuesta sobre la importancia del fortalecimiento de competencias}

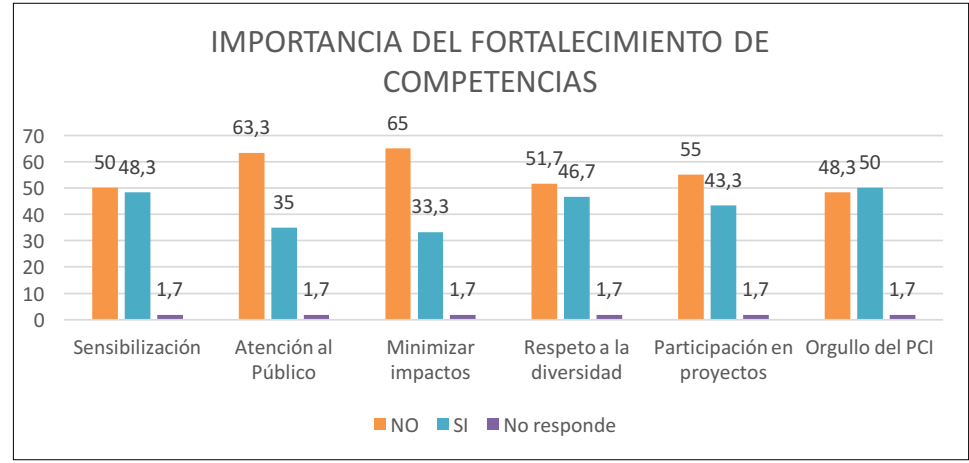

Fuente: Elaboración propia

Por otro lado, la ejecución del taller se llevó a cabo mediante la solicitud de un espacio en el Centro Cultural Metropolitano. Se determinaron las fechas y horas de realización del taller para la elaboración y entrega de las invitaciones a los actores sociales claves del Centro Histórico de Quito.

\section{Figura $\mathrm{N}^{\circ}$ 7: Invitación a los custodios del PCI}

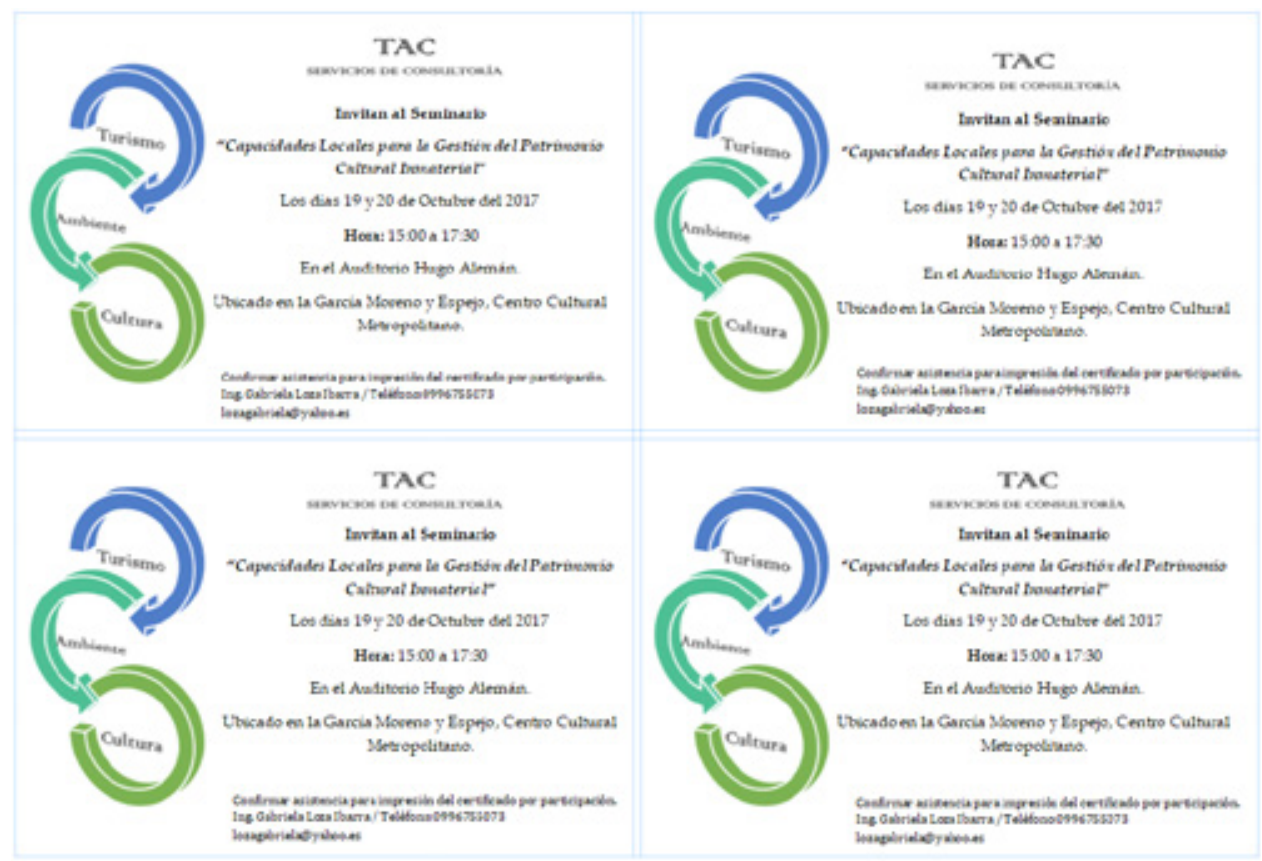


Con base en los resultados obtenidos en la encuesta anterior, se determinó la importancia de la temática a tratar en los días del taller:

- Patrimonio cultural inmaterial y su importancia.

- Salvaguardia del patrimonio cultural inmaterial.

- El patrimonio cultural inmaterial, una alternativa para el sector productivo.

- Gestión local del patrimonio cultural inmaterial.
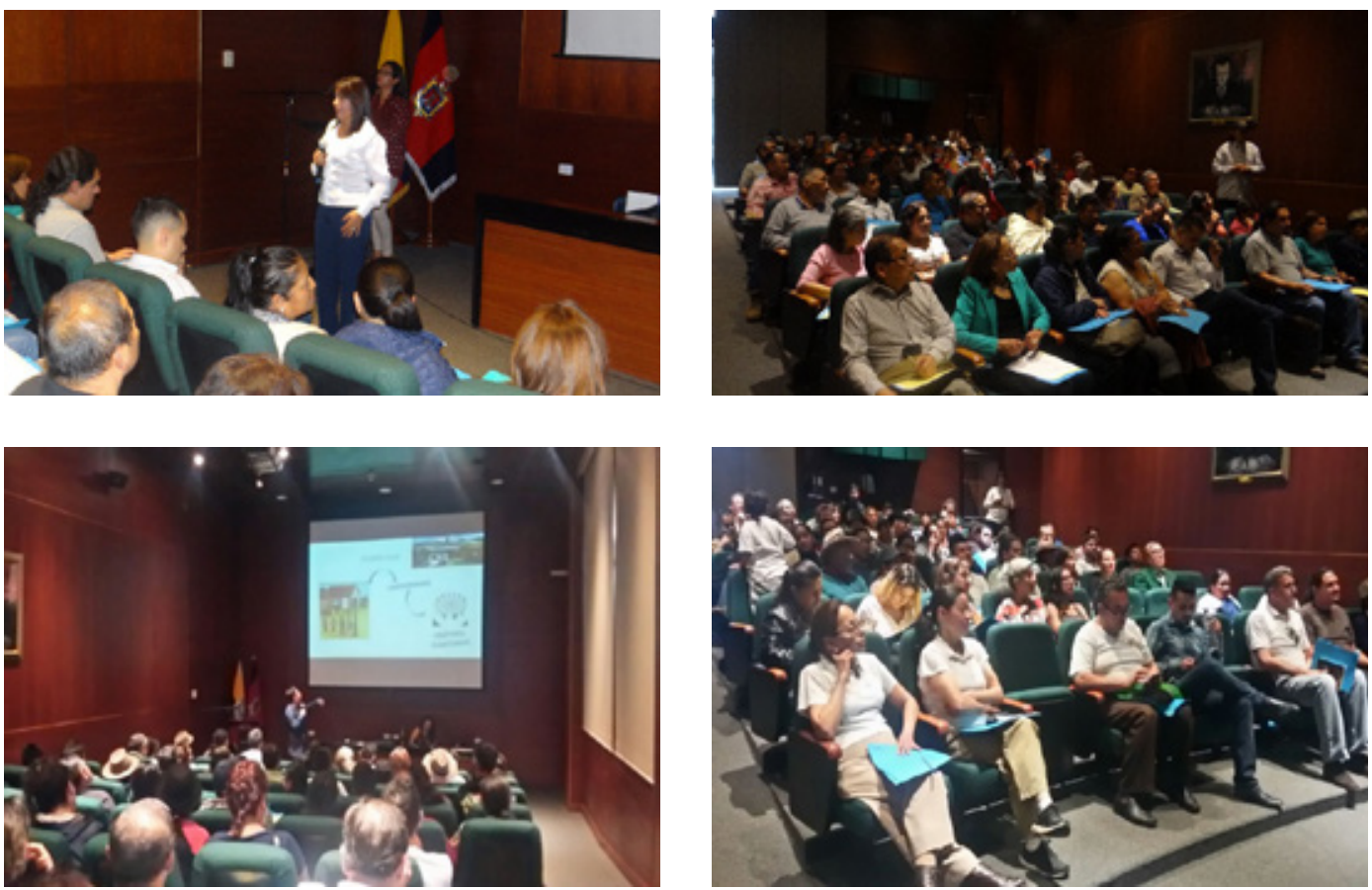

Paso 10. La propuesta cultural fue ingresada en la página web de la Secretaría de Cultura con el objetivo de visibilizar a detentores, custodios y practicantes del PCI que mantienen vivo el Centro Histórico de Quito. Se solicitó el uso de un espacio en el Centro Cultural Metropolitano con la finalidad de realizar dos ferias, las que se desarrollarán en los meses de septiembre y noviembre, tomando en consideración la Declaratoria de Quito Patrimonio Cultural y el mes del artesano. El presupuesto solicitado para los dos eventos se solicitó sobre la base de los requerimientos y necesidades para su realización. Además, se consideró un acto protocolar donde se entregarán placas de reconocimiento a los detentores, custodios y practicantes del PCI que colaboraron con la investigación durante estos dos años.

\section{Conclusiones}

Las ciudades patrimonio de la humanidad guardan en sus cascos históricos su patrimonio cultural inmaterial, el cual, requiere la atención particular y diferenciadora del resto de la cultura y patrimonio, por la importancia, interés y por ser el nexo que disponemos las poblaciones actuales para conocer el pasado y proyectarnos al futuro.

Generar políticas, planes y programas de promoción, conservación y salvaguardia del PCI que permitan la práctica y recuperación de los valores simbólicos de la ciudad, mediante el uso del espacio público destinado al dialogo cotidiano, construcción colectiva y transmisión de saberes. Esto permitirá visibilizar el patrimonio inmaterial de las ciudades y territorios que preservan aún ésta riqueza.

Los detentores y custodios del PCI son el recurso endógeno de las ciudades patrimonio de la humanidad. Actores que merecen el reconocimiento por su práctica, transmisión de conocimientos y técnicas 
ancestrales de generación a generación a través de la oralidad. Además, ésta oferta cultural amerita urgentemente un acercamiento con el sector productivo como mecanismo de visibilización y puesta en valor del patrimonio inmaterial.

Un logro importante en el Ecuador es la generación de diagnósticos y herramientas, así como la generación de espacios de diálogo, debate y sensibilización en la población sobre el PCI, instrumentos generados por los organismos del Gobierno Central, al tiempo que, en el futuro inmediato, habrá de encaminar esfuerzos para que estos planteamientos, alcancen el eco en la gestión de los gobiernos locales, en el marco de sus actuales competencias sobre el patrimonio cultural en sus territorios.

\section{Bibliografía}

Arizpe, L. 2011. El Patrimonio Cultural Inmaterial de México. Ritos y Festividades. México: Editorial: Miguel Ángel Porrua.

Arrom, J. 2010. El turismo cultural en Mayorca: Recursos, productos y potencialidades. España: Editorial: Palma.

Camarero Izquierdo C. 2008. Marketing del Patrimonio. España: Editorial Pirámide.

Cañizares, Brian. 2013. Actores sociales: claves analíticas para una aproximación problematizadora. Centro de Estudios Interdisciplinarios en Problemáticas Internacional y Locales. Tandil.

Carvalho, K. y Guzmán, S. 2011. El turismo en la dinámica territorial. ¿Lógica global, desarrollo local? Estudios y perspectivas en turismo.

Coloma, F. 2012. Bases y estrategias de la gestión cultural: derechos culturales para el buen vivir. Quito: Casa de la Cultura Ecuatoriana Benjamín Carrión.

Consejo Nacional para la Cultura y las Artes. s.f. Patrimonio Cultural Inmaterial y Turismo: Salvaguardia y Oportunidades. México: S/E.

Cuenca, L. A. 2013. Patrimonio Cultural, El ABC. Maracaibo: Universidad de Zulia.

CONAGUA - Gobierno Federal. Estados Unidos Mexicano. s/a. Guía Identificación de actores clave. México D.F.

Gobierno Autónomo Descentralizado Parroquial de Tarqui 2011. Modelo de Gestión Participativa del Territorio.

González, M. V. 23 de Abril de 2009. Gestión Turística del Patrimonio Cultural: Enfoques para un Desarrollo Sostenible del Turismo Cultural. Recuperado el 15 de Octubre de 2015 de https://digitum. um.es/xmlui/bitstream/10201/15453/1/67591.pdf

Instituto Nacional de Patrimonio. 201). Guía Metodológica para la Salvaguardia del Patrimonio Cultural Inmaterial. Recuperado de http://www.inpc.gob.ec/images/Descarga/libros/salvaguardiainmaterial.pdf.

Instituto Nacional de Patrimonio Cultural 2014. Patrimonio Cultural Inmaterial. Recuperado de: https:// issuu.com/inpc/docs/folleto_patrimonio_inmaterial

Instituto Nacional de Patrimonio Cultural 2014. Sistema de Información del Patrimonio Cultural Ecuatoriano (SIPCE). Recuperado de: https://www.patrimoniocultural.gob.ec/sistema-de-informacion-del-patrimonio-cultural-ecuatoriano-sipce/

Macarrón, A. 2008. Conservación del Patrimonio Culural, criterios y normativas. Madrid - España: Editorial Síntesis

Mejía, J. 2010. Política para la Gestión, protección y salvaguardia del Patrimonio Cultural. Recuperado de: http://www.mincultural.gov.co/ministerio/políticas-culturales/gestionproteccionsalvaguardia/ Documents/02_politica_gestion_proteccion_salvaguardia_patrimoniio_cultural.pdf.125

Ollero, F. 2010. Patrimonio Cultural, identidad y ciudadanía. Quito - Ecuador: ABYA - YALA.

Plan Nacional de Desarrollo 2017-2021. Toda una Vida. Secretaria Nacional de Planificación y Desarrollo - Senplades 2017. Quito - Ecuador. Recuperado de: https://www.planificacion.gob.ec/wp-content/ uploads/downloads/2017/10/PNBV-26-OCT-FINAL_0K.compressed1.pdf

Romero, C. 2001. Ciudad, cultura y turismo: calidad y autenticidad. España: Instituto Andaluz del Patrimonio Histórico.

UNESCO, 1972. Convención sobre la protección del patrimonio mundial, cultural y natural. Recuperado de: http://whc.unesco.org/archive/convention-es.pdf.127

UNESCO, 1982. Declaración de México sobre las políticas culturales - Conferencia mundial sobre las Políticas Culturales. Recuperado de: http://portal.unesco.org/culture/es/files/35197/11919413801mexico_ sp.pdf/mesico_sp.pdf. 
UNESCO, 2001. Declaración Universal de la UNESCO sobre la Diversidad Cultural. Recuperado de http://www.cinu.mx/eventos/127162s.pdf.

UNESCO 2001. Declaración Universal de la UNESCO sobre la Diversidad Cultural. Recuperado de: http://portal.unesco.org/es/ev.php-URL_ID=13179\&URL_DO=DO_TOPIC\&URL_SECTION=201.html

UNESCO, 2003. Convención para la Salvaguardia del Patrimonio Cultural Inmaterial. París: S/E

UNESCO, 2003. Convención para la Salvaguardia del Patrimonio Cultural Inmaterial. Recuperado de: http://unesdoc.ubnesco.org/images/0013/001325/132540s.pdf.

UNESCO 2003. ¿Qué es el patrimonio cultural inmaterial? Recuperado de: https://ich.unesco.org/doc/ src/01851-ES.pdf

UNESCO, 2009. Captar lo inmaterial, una mirada al patrimonio vivo. París: Organización de las Naciones Unidas para la Educación, la Ciencia y la Cultura.

Viladevall, M. 2003. Gestion del Patrimonio Cultural. México: BUAP. 